\title{
Semantic map approach to universals of conceptual correlations: a study on multifunctional repetitive grams
}

Ying Zhang (D)

Correspondence: yzhangbc@connect.ust.hk

Division of Humanities, Hong Kong University of Science and

Technology, Kowloon, Hong Kong

\begin{abstract}
There are some frequently used Chinese adverbs that display such a high degree of multifunctionality that the usage categorizing and the semantic connective pattern have long been a disputed issue, such as the repetitive adverbs 還 hai 'still', 再 zai 'again' and 又 you 'again, also'. However, if attention could be turned from the nuances of usages within a single language to the notions these adverbs share cross-linguistically, it would be noticed that the notions expressed by these three adverbs like Repetition, Supplement and Increment could also be found in the repertoire of the counterparts in languages from completely different language families. The recurrence of these notions is by no means an accident; instead, the notions are to be related to each other in a certain fashion that could be specified. The Semantic Map Model (SMM) is just a tool that can best unravel the universal connective pattern. Based on first-hand data collected from 40 languages and second-hand data from reference grammar of 38 languages, a conceptual space centering on the concept of Repetition is established in this research. With the insight obtained from constructing this conceptual space, we also exemplified how this SMM approach benefits us in dealing with some long-standing puzzles with respect to Chinese repetitive adverbs.
\end{abstract}

Keywords: Semantic map model, Repetitive adverbs, Multifunctionality

\section{Background}

Due to a high degree of polysemy, the usage categorizing of some multifunctional Chinese adverbs has long been a subject of dispute. Take the adverbs 還 hai 'again, still, 再 zai 'again, more', and 又 you 'again, also' as examples, all of them can express the function of Repetition, ${ }^{1}$ in which cases all of them can be rendered into English again. Besides, as also suggested by the glossings, they each have their own particular functions, like the Continuation function of hai, in which case hái is similar to English still and it refers to "an extension of a state of affairs up to an utterance time" (Michaelis 1996: 179). Apart from Repetition, adverb zai can also denote the function of Increment which demonstrates an additional quantified action like in the expression 再吃一個蘋果 zai chi yige pingguo 'eat one more apple'. Likewise, you can also deliver functions other than Repetition. For example, you can express the function of Supplement to show a parallel different action that has been added to a preceding one:

(c) The Author(s). 2017 Open Access This article is distributed under the terms of the Creative Commons Attribution 4.0 International License (http://creativecommons.org/licenses/by/4.0/), which permits unrestricted use, distribution, and reproduction in any medium provided you give appropriate credit to the original author(s) and the source, provide a link to the Creative Commons license, and indicate if changes were made. 
她吃完蘋果又吃了一個梨 ta chi wan pingguo you chi le yi ge li 'she ate an apple and then ate a pear as well'. In fact, each of the three adverbs can express far more functions than what have depicted above. Early in Wang 王力 (1944), it has already been pointed out that the adverbs ye and you have multiple uses in diverse contexts. Since then, the issue of what those multiple uses are and how to categorize them became the most disputed issues in early research (Biq 1989; Lü 吕叔湘 1980; Shao and Rao 邵敬敏, 饶春华 1985; Shi 史 锡尧 1990, 1996; The 1955/1957 Language Class, Department of Chinese Language and Literature, Peking University, 北京大学中文系1955/1957语言班 1982).

However, if attention could be turned from the nuances of usages within a single language to the notions these adverbs share cross-linguistically, it would be noticed that the various functions expressed by Chinese hai, zai or you could also be found in the repertoire of German noch, Ghomálá bing, Saisiyat nahan etc. Take noch and bing as examples.

\section{Repetition-Inverted Sequence-Increment-Greater Degree-Continuation-Decrement} (German: Germanic, Indo-European)

(1) Bitte__sag_es__noch_einmal.

please_say_it_more_once

Please say it one more time. ${ }^{2}$

(2) Lassen__sie_uns_noch_einmal_

$\mathrm{zu} \_\mathrm{dem} \_$vorherigen_problem_zurückkehren.

let_2SG_1PL_again_once_to_the_previous_problem_return

Let us get back to the previous problem.

(3) Iss_noch_einen_apfel.

eat_more_one_apple

Eat one more apple.

(4) Er_kann_noch_schneller_laufen.

3SG_can_even_fast.CM_run

He can run even faster.

(5) Als_er_anrief, badete_ich_noch.

when_3SG_call.PST, bath. PST_1SG_still

When he called, I was still taking a bath.

(6) Ich_habe_noch_geld_übrig.

1SG_have_still_money_left

I still have some money left.

\section{Repetition-Inverted Sequence-Increment-Greater Degree-Supplement}

(Ghomálá: Volta-Congo, Atlantic-Congo)

(7) Susso__bing_ghom.

please_again__say

Please say (it) again.

(8) Pe_bing_goh_ne_yim_nuo be.

2PL_again__go_to_previous_problem.

Let us get back to the previous problem.

(9) Bing_fa_tom. 


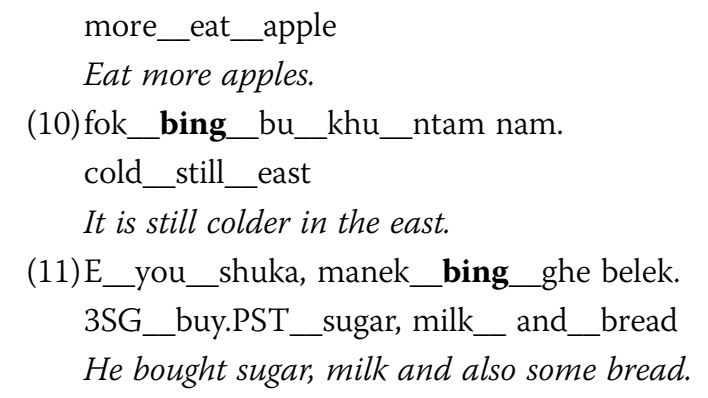

From the above, we could see that these functions could also be expressed by one expression in languages other than Chinese. In other words, these functions tend to be expressed by one form across different languages. As the languages are from completely different language families, the recurrence of these functions is by no means an accident; instead, the functions are to be related to each other in a certain fashion that could be specified. Enlightened by this cross-linguistic fact, we find it very promising to explore the Chinese multifunctional repetitive adverbs from the typological perspective as it may not only provide solutions in solving the disputed semantic issue within Chinese but could also reveal the conceptual correlations that reflect the human cognition at large.

This study takes the Chinese multifunctional repetitive adverbs hai, you and zai as a point of departure, analyzes the concepts that they could express and attempts to reveal the universal pattern that these concepts are connected by comparing the counterparts of the three Chinese adverbs in 69 other languages.

To prepare the ground for further discussion, we will address the following three issues in the rest of the intro part. The first issue is why we choose hai, you and zai as the starting point rather than other Chinese adverbs. The second one is why and how we use the cross-linguistic approach to determine corresponding conceptual correlations. The last part will be a brief literature review on studies that use the similar approach to solve the relevant issues.

This study is one of three paralleled research projects on Chinese multifunctional adverbs in the cross-linguistic perspective. The three independent studies are about repetitive adverbs (hai, zai and you), additive adverbs (都 dou 'all' and 也 ye 'also') and restrictive adverbs (就 jiu 'just, at once', 才 cai 'only, not until', 剛 gang 'just, as soon as' and 將 jiang 'be about to, merely'), respectively. In the following, we will introduce the criterion and procedure in identifying these adverbs as the research objects.

The primary criterion is multifunctionality because the mono-functional word does not suggest any conceptual correlation at all. ${ }^{3}$ Following this principle, we have examined all the 498 Chinese adverbs listed in Zhang 张谊生 (2000: 21) and have ruled out those mono-functional adverbs according to the explanations in Lü 吕叔湘 (1980). We are then left with 50 multifunctional adverbs. These 50 multifunctional adverbs are then filtered by the second-round selection by the criteria of syllable numbers and word frequency. Ultimately, we are left with three groups of adverbs as mentioned above. Due to lack of space, we restrict our discussion to the first study on hai, zai and you in this paper.

Now, we would like to move to the second issue about why we take a cross-linguistic perspective and in what way it can benefit our understandings towards Chinese repetitive adverbs. 
Take one of the Chinese repetitive adverbs hai as an example. Due to its complex semantic behaviors, the usage categorizing of hai has long been a subject of much dispute (Gao 高順全 2011; Gao 高增霞 2002; Gao and Gao 高思欣, 高思艳 2007; Guo 郭锐 2008; Li 李东梅 2015; Li and Thompson 1981; Liu 2000; Shao 邵洪亮 2013; Shen 沈家煊 2001; Shi 史锡尧 1996; Tong 童晓娥 2004; Wu 武果 2009; Xie 谢白羽 2011; Yeh 1998; Zhao 赵淑华 $1981^{4}$ ). Each of these studies has a different focus and has yielded different insights about adverb hai. However, all these studies share one thing in common that the usage categorizing and the usage connective pattern of hai are derived from the introspective inquiry of the researcher. Therefore, it is frequently observed that different researchers may come up with different analyses concerning the semantic behavior of hai (Fig. 1). For instance, following traditional semantic analysis, Shi 史锡尧 (1996) concludes a semantic network of hai as follows:

However, we may also observe a quite different semantic network as suggested by Gao and Gao 高思欣, 高思艳 (2007) (Fig. 2).

When we come across the discrepancies as shown above, it is difficult for us to evaluate which analysis is more superior than the other. The reason is that analyses based on personal inquiries are not easy to be verified or falsified. Therefore, we need to take recourse to other analytical method that relies on independent sources. What is more, an ideal situation is once a study based on this independent group of source is proposed, subsequent studies that based on the same group of source and methodology could also be conducted to test the validity of the previous one. In other words, the study should be repeatable and verifiable.

The cross-linguistic comparison is just an ideal approach to achieve this goal. When trapped in a dilemma of determining whether two functions are directly connected, we let the cross-linguistic data tell us the answer to avoid unnecessary bias caused by subjective semantic analysis.

For example, if we want to explore how the functions of Repetition, Increment and Greater Degree are connected, we can examine the multifunctional forms in different languages that can deliver these functions. If Repetition and Increment always tend to be expressed by one linguistic form in different languages, chances are high that these two functions are closely connected. Akhar in Arabic and lagi in Malay are examples among many others that use one form to denote both Repetition and Increment, which suggests that these two function nodes should be directly linked. In the same vein, if Increment and Greater Degree tend to be subsumed under one linguistic form in different languages, these two notions are also proved to be adjacent to each other. Deo in Korean and mais in Portuguese are examples of this group of data. Now, we can obtain a minimal pattern about how these three concepts are connected by the abovementioned two groups of data (Fig. 3). ${ }^{5}$

In fact, this approach is just how we will present the outcome of cross-linguistic comparison in this research. It is called Semantic Map Model (SMM). As illustrated by

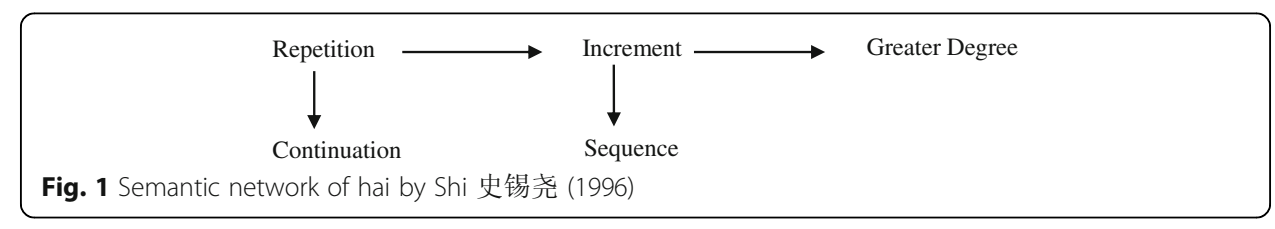


Repetition $\longrightarrow$ Greater
Fig. 2 Semantic network of hái by Gao and Gao 高思欣, 高思艳 $(2007)$

Haspelmath (2003: 213), "a semantic map is a geometrical representation of functions in 'conceptual/semantic space' which are linked by connecting lines and thus constitute a network". In this network, the more similar the functions are, the closer they are located in the map. As the semantic map is derived from cross-linguistic comparison, it is believed to represent "a universal structure of conceptual knowledge (Croft 2001: 105)"; therefore, the configuration shown by the semantic map "is claimed to be universal (Haspelmath 2003: 213)".

Apart from the universals, the semantic map could also represent language-particular facts. There is a basic working principle to set up a semantic map-- "semantic connectivity hypothesis". It requires that the functions expressed by a language-particular category should occupy a contiguous area in the semantic map. It is equal to say for each language-specific category, it could "map onto connected regions (Croft 2001: 105)". Therefore, for akhar in Arabic and lagi in Malay which express both Repetition and Increment, we can show its boundaries in the semantic map as follows (Fig. 4):

Likewise, the boundaries of deo in Korean and mais in Portuguese could also be represented in the map (Fig. 5).

Therefore, the language universals about how concepts are connected are reflected by the whole structure of the semantic map, whereas the particularity of languages could also be demonstrated by the map as the functions of a form would be represented by a contiguous smaller area of the original semantic map. To better differentiate these two types of pattern, we will call the former one, the universal connecting configuration as "conceptual space" (such as Fig. 3) whereas the latter one, the bounded region in the configuration for a language-particular form as "semantic map" (such as Figs. 4 and 5) in this research.

If we adopt this cross-linguistic perspective and the representing tool of SMM, many puzzles in the analysis of particular issues in particular language seem more tractable. As illustrated by the relation of "conceptual space" and "semantic map" above, the connective pattern shown by a conceptual space is universal, and different grammatical forms in different languages only split the same conceptual space into different contiguous parts. Undoubtedly, hai in Chinese is no exception to this. The functions expressed by hai should also occupy a connective area in the conceptual space. In so doing, the semantic map of hai is defined. What is more, the configuration of this semantic map is exclusive.

Compared with the semantic network proposed in the monolingual perspective, the semantic map constructed in this cross-linguistic perspective has a number of advantages. Firstly, it does not have any theoretical commitment and is relatively more objective. As introduced above, whether two functional nodes be connected or not in a conceptual space is completely based on cross-linguistic data. Secondly, what the

\begin{tabular}{|c|c|c|}
\hline Repetition & Greater Degree \\
Fig. 3 Connective pattern of Repetition, Increment, and Greater Degree
\end{tabular}


\begin{tabular}{|lll}
\hline Repetition Increment & Greater Degree \\
\hline
\end{tabular}

Fig. 4 The boundaries of Arabic akhar and Malay lagi

semantic map reflects is far more than what the semantic network demonstrates. The former one is derived from large-scale cross-linguistic data, and it not only shows how the different functions are connected in a particular language but also reflects how these functions are connected in the conceptual level. In other words, it reflects the "universal structure of conceptual knowledge". By contrast, the latter approach apparently cannot provide this universal semantic relationship. Besides, the semantic map approach can also generate a number of implicational universals. For instance, for the minimal conceptual space illustrated in Fig. 3, it entails that "if a language form can denote both Repetition and Greater Degree, it can express the notion of Increment as well". Thirdly, the semantic map can offer assessment for existing paradox semantic networks. As the semantic map is independent of traditional semantic analysis, it can objectively evaluate whether a semantic link proposed by the semantic analysis is valid or not. Last but not the least, as the SMM approach is based on cross-linguistic data, it is highly probable that different researchers will produce the same conceptual space. Even if researchers based on completely different range of data, it is proved that the main frames of the conceptual spaces remain the same. One can compare the conceptual space based on languages of the world in Haspelmath (2003) and the one based on Xiang dialect in China in Zhang 张敏 (2010). However, for semantic networks that based on personal inquiries, it is intractable to repeat it by another researcher. Even if it is managed to redone by the same analyzing approach, the outcome of the semantic analysis is highly possible to be varied from the original one.

Due to the above reason, we will adopt the SMM approach to construct a conceptual space centering on the notion of Repetition in this research, and at the end of this research, we will also illustrate how it helps us to solve what the previous approaches fail to solve.

In the last part of this introduction, we will briefly introduce the existing SMM studies and the significance of exploring the multifunctional Chinese adverbs in this approach.

In the past two decades, SMM has received an increasing popularity among typological study. Ever since Anderson applied this model to the study of the area of perfect (Anderson 1982), this approach has been widely used in a great many of other grammatical fields, like evidentiality (Anderson 1986), voice (Kemmer 1993), case (Croft 1991), modality (van der Auwera and Plungian 1998; De Haan 2005; Fan 范晓蕾 2011), indefinite pronouns (Haspelmath 1997) and dative (Haspelmath 2003; Zhang 张敏 2010). However, few attempts have been made in the area of adverbs via this SMM approach.

One possible account for the deficiency of this line of research on adverbs may lie in the different derivational methods of adverbs. To many typologists, the most familiar languages are Indo-European languages. In these languages, most adverbs are derived from adjectives through a morphological process. Therefore, adverbs are recognized as an open-class item, which could be highly productive. This proliferative feature of

\begin{tabular}{|l|l|}
\hline & Repetition \\
& Increment \\
Fig. 5 The boundaries of Korean deo and Portuguese mais
\end{tabular}


adverbs in Indo-European languages makes it quite an obstacle to conduct large-scale cross-linguistic comparisons. Besides, this regularity also makes this topic theoretically uninteresting. However, adverbs in Chinese are quite opposite. Due to the lack of morphological change, adverbs in Chinese are more prone to be deemed as close-class or at least half-open half-close items. Besides, the multifunctionality of the frequently used Chinese adverbs is highly irregular which makes it also a very intriguing research topic.

The differences depicted above have answered why there is a lag in the present typological research on adverbs but also have explained why it is a privilege to conduct this kind of cross-linguistic research by employing Chinese adverbs as the cutting-in point.

\title{
2 Previous research
}

To our best knowledge, there is only one attempt of applying SMM to the study of adverbs. Based on intrinsic semantic analysis, Guo 郭锐 (2010) sets up a conceptual space on the functions delivered by a couple of Chinese multifunctional adverbs.

There are two critical terms that the author employed to interpret the bifurcations among different concepts expressed by the Chinese adverbs. One is "semantic element," and the other is "semantic structure". Early in Guo 郭锐 (2008: 9), the concepts of "semantic element" and "semantic structure" were introduced to explain the functions of Repetition and Inverted Sequence of Chinese hai. For example:

\section{Repetition}

(12)这个电影我还要看一遍。 zhege_dianying_wo_hai_yao_kan_yi_bian this_movie_1SG_again_want_watch_one_CLF

This movie I want to see it again.

\section{Semantic element}

\{time point a, time point b\} \{situation Ea, situation Eb\}

\section{Semantic relation}

Time point $\mathrm{a}$ is earlier than time point $\mathrm{b}$;

Situation Ea is identical to situation Eb;

Time point $\mathrm{a}$ and time point $\mathrm{b}$ is discontinuous.

\section{Inverted Sequence}

\author{
(13) 人死了还会活过来吗? \\ ren_sile_hai_hui_huo_guolai_ma \\ people_die.PFV_again_will_alive_COMP_SFP \\ Will people be alive again after (s)he died?
}

\section{Semantic element}

\{time point a, time point $\mathrm{b}$, time point $\mathrm{c}\}$ \{situation Ea, situation Eb, situation Ec\}

\section{Semantic relation}

Time point a is earlier than time point c; 
Situation Ea is identical to situation Ec;

There is a situation Eb in between Ea and Ec.

"Semantic element" plus "semantic relation" is defined as "semantic structure" in Guo 郭锐 (2008). It is argued that the more similar two semantic structures are, the more adjacent the two related notions are in the conceptual space. In light of this principle, a conceptual space which shows the connecting pattern of 19 notions is proposed based on the analysis of all the notions that could be expressed by the multifunctional adverbs of hai, ye, zai, and you (Fig. 6).

The above conceptual space was then checked by the data from 26 other languages. It is found that all the functions of the adverbs examined could occupy a contiguous area in the above conceptual space except Zhuang and Spanish. According to the data from Zhuang and Spanish, the notions of Greater Degree and Supplement should be linked together to satisfy the "semantic map connectivity hypothesis". Besides, data from Zhuang and Spanish also suggest that expressions for Supplement could also denote Increment. Therefore, a new notion Increment should be added. The original conceptual space is thus revised as follows (Fig. 7):

However, there are several factors threatening the validity of the above semantic map. Firstly, the notion Increment is added afterwards only to cater for the semantic map connectivity hypothesis. Therefore, the connections of Increment with other notions might not be as robust as the others. Secondly, there are only three multifunctional grams involving the notion of Increment, which evidently requires further verification by more cross-linguistic data. Finally, the data we have collected demonstrates that there are some multifunctional grams representing the concepts of Repetition and Increment only. For instance:

\section{Increment-Repetition}

(Hui Chinese [Qimen]: Sinitic, Sino-Tibetan)

(14) 尔吃碗凑。

n_t t ${ }^{\mathrm{h}} \mathrm{i}: \partial \_n \tilde{u}: \partial \_t s^{\mathrm{h}} \mathrm{e}$

2SG_eat_bowl.CLF_more

You should eat one more bowl (of food).

(15) 尔再讲遍凑。

$$
\text { n_tsa_k } \mathbf{z} \_ \text {pĩ:ə_ts }{ }^{h} \mathbf{e}
$$

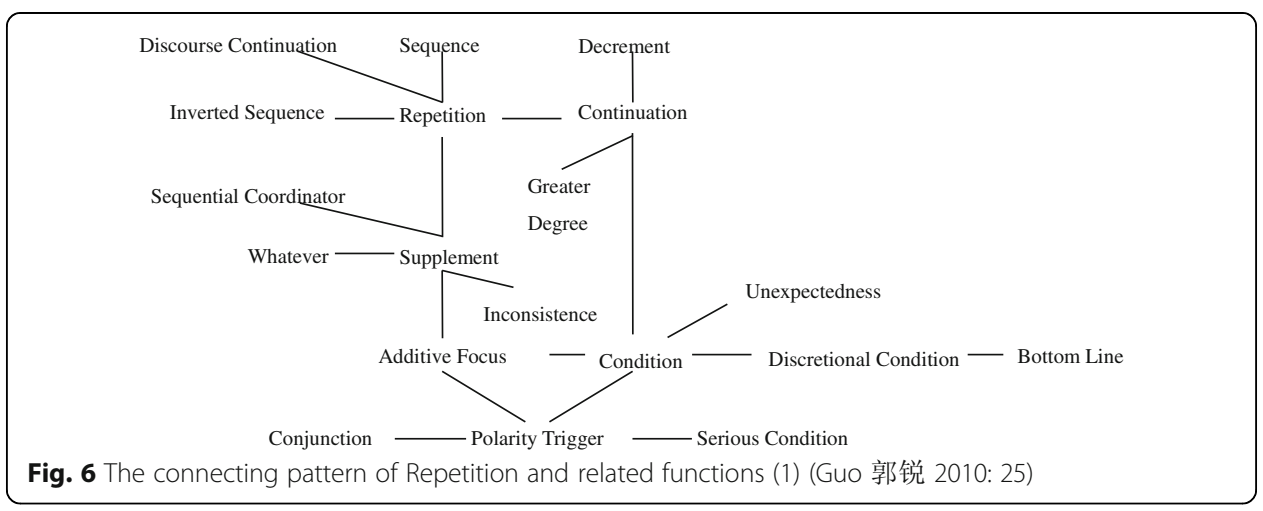




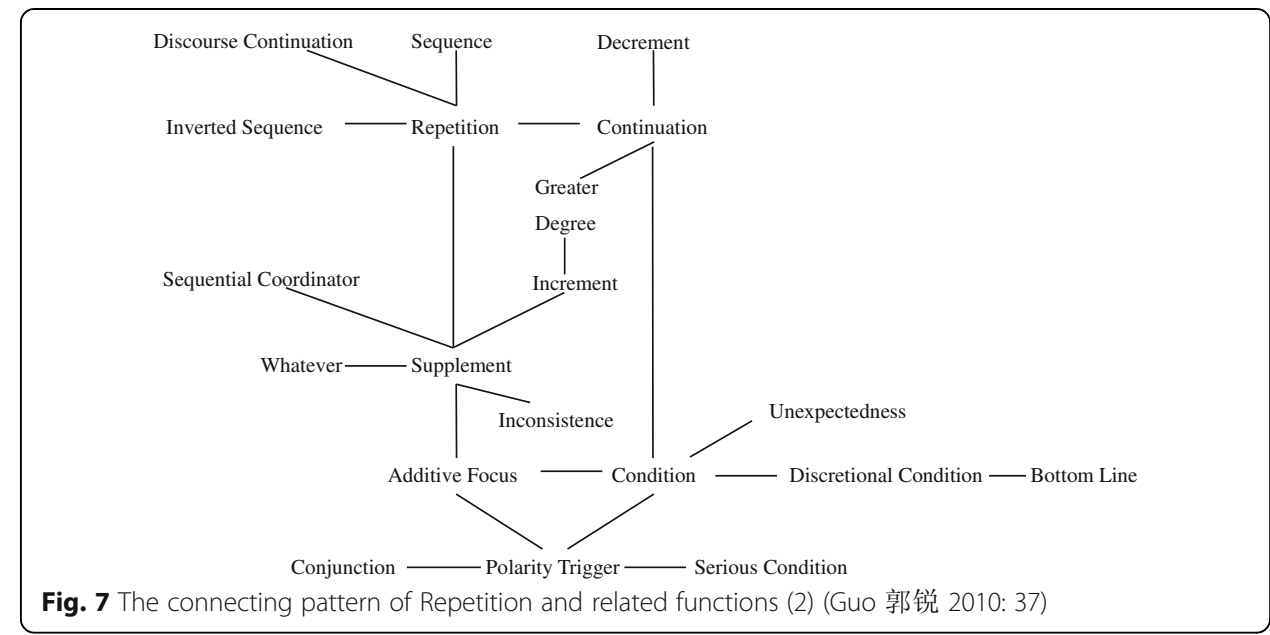

2SG_again_say_time.CLF_more

Say it one more time. (Akitani 秋谷裕幸 2005)

\section{Increment-Repetition}

(Min Dong Chinese [TaiShun]: Sinitic, Sino-Tibetan)

\section{(16)大概蜀下囝添就讲好了。}

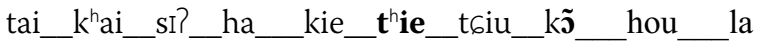

$$
\begin{aligned}
& \text { perhaps_a moment_more_then_say_PFV_SFP }
\end{aligned}
$$

(17) 请你讲调添!

$$
\begin{aligned}
& { }^{\mathrm{t}}{ }^{\mathrm{h}} \text { ian__n_k }{ }^{\mathrm{N}} \text { _tieu_t }{ }^{\mathrm{h}} \mathbf{i e} \\
& \text { please_2SG_say_time.CLF_more }
\end{aligned}
$$

Please say it one more time! (Akitani 秋谷裕幸 2005)

In light of the "semantic map connectivity hypothesis," Increment and Repetition should occupy a contiguous area, as is suggested by the aforementioned language example; however, this contradicts the pattern shown in the semantic map in Guo 郭锐 (2010), in which the two notions are not adjacent. Therefore, a separate study based on a larger data set is needed to see whether there would be differences in terms of the connecting pattern.

Another problem that prompts us to conduct a similar but independent study on this topic comes from an issue of methodology. As noted above, the conceptual space in Guo 郭锐 (2010) was originally set up by pure semantic analysis and was adjusted slightly to account for cross-linguistic data. This approach is not quite consistent with the usual practice of cross-linguistic studies in which pure cross-linguistic data is the main source from which a connecting pattern is deduced. Though "semantic element" and "semantic structure" are applied in the analysis of the different functions, the particularity of each interpreting fashion makes it hard to avoid personal bias in the defining of each notion. Therefore, it is meaningful to explore new ways to differentiate the nuances of the repetitive adverbs and provide an objective evaluation on the two approaches of establishing a conceptual space. 


\section{The semantic notions expressed by the repetitive adverbs}

By comparing cross-linguistic data of the equivalences of hai, you, and zai, eight notions have been identified and will be defined and analyzed below. They are Increment, Repetition, Sequentiality, Inverted Sequence, Greater Degree, Continuation, Decrement, and Supplement. As these notions are not widely recognized, we feel obliged to offer some parameters by which similar notions could be better differentiated. What is more, to avoid possible arbitrariness, all the notions will be analyzed under a unified framework which contains parameters from six dimensions: "quantified", "increasing", "similar", "bounded", "future-oriented", "sequenced."

We will examine each of the notions by the six parameters and label the notions accordingly. For example, if the notion entails the semantic feature of "quantified", it will be labeled as [+quantified]; if it excludes this feature, it will be labeled as [-quantified]; if the feature is extraneous to the semantics of a specific notion, it will be represented as $[ \pm$ quantified] accordingly.

\subsection{Increment}

Increment means to add the same type of quantified action to the previous one. As the newly added action has not happened yet, we call it "future-oriented". The first and second actions should have a clear boundary, which means the two actions are discrete rather than continuous. Syntactically, it always co-occurs with numeral classifier phrases. For example:

\section{(Hakka Chinese [Lian Cheng]: Sinitic, Sino-Tibetan)}

(18) 食一碗饭添。

$$
\text { sik_jat_wun_faan_tim }
$$

eat_one_bowl.CLF_rice_more

Eat one more bowl of rice. (Xiang 项梦冰 1997)

The semantic feature bundles of Increment could be illustrated by [+quantified][+increasing][+similar][+bounded][+future-oriented].

\subsection{Repetition}

Repetition simply demonstrates a repetition of a previous action, and boundaries also exist between the new action and the previous one. The difference between Increment and Repetition lies in that the former notion emphasizes the quantity of the object whereas the latter says nothing or does not care about the quantity of the object. This distinction is seen in the following example:

\section{(Lahu: Burmo-Qiangic, Sino-Tibetan)}

(19) 你明天再来吧。

$$
\begin{aligned}
& \text { nJ_s __p__x __q_a_la_lum } \varepsilon \\
& \text { 2SG_tomorrow_aux_again_come_AUX } \\
& \text { You can come again tomorrow. (Chang 常宏恩 1986) }
\end{aligned}
$$

The semantic feature bundles would be $[ \pm$ quantified $][+$ increasing $][+$ similar $][+$ bounded][+future-oriented]. 


\subsection{Sequentiality}

The natural time sequence is addressed by this notion, which means to add a different action that occurs later to an earlier one. Also, the added action is often one that has not been realized, so it is also "future-oriented". For instance:

\section{(Dong: Kam-Tai, Tai-Kadai)}

(20) yaoc_sagl_ugs_unv_siip_bail_xugs_mal 1 SG_wash_clothes_first_then_go_wash_vegetable I will wash the clothes first and then clean the vegetables. (Yang and Zhang 杨汉基, 张盛 1993)

The semantic feature bundles should be generalized as [-quantified][+increasing][-similar][+bounded][+future-oriented][+sequenced]

\subsection{Inverted Sequence}

Inverted Sequence illustrates an opposite sequence from the Sequentiality just described above. It adds another different action that has happened at an earlier stage or time. For instance:

\section{(Yue Chinese [Hong Kong]: Sinitic, Sino-Tibetan)}

(21)我地傾返頭先個個問題。 ngo-dei_king_faan_tausin_go_go_mantai. 1PL_talk_back_previous_that_CLF_problem Let us get back to the previous problem.

The semantic feature bundles would be $[-$ quantified $][+$ increasing $][-$ similar $][+$ bounded][+future-oriented]][-sequenced].

If we observe the above sentences from the perspective of the "aktionsart" of the predicate in it, we will find that all the four notions mentioned above refer to actions, where the predicates of the sentences are all core verbs, like "eat" and "come". On the contrary, the following four notions are related to properties and states, with most of the predicates being expressed by adjectives.

\subsection{Greater Degree}

Greater Degree raises the level of the property, and it also mostly appears in futureoriented sentences. For example:

(Yue Chinese [Hong Kong]: Sinitic, Sino-Tibetan)

(22) 你仲要畋畋男添。 nei_zung_jiu_nau_nau_tim 2SG_still_get_angry_angry_more

You must still get a little angrier than before. 
It can be described by the semantic feature bundles as $[ \pm$ quantified] [+increasing] [+similar][-bounded][+future-oriented].

\subsection{Continuation}

Continuation shows that the property or the state continues over time.

\section{(Korean: Koreanic)}

(23)wuli_emeni-nun_acik_celm-usi-eyo

our_mother-TC_still_young-SH-POL

My mother is still young. (Sohn 1994)

In the above example sentence, acik expresses the notion of Continuation, which means that the state of "young" continues to the reference time. The semantic feature bundles of Continuation could be represented as [-quantified][ \pm increasing][+similar][-bounded][-future-oriented].

\subsection{Decrement}

Decrement simply illustrates the fact that a quantity decreases as some parts of it are eliminated.

\section{(Lachi: Kadaic, Tai-Kadai)}

(24) ua_m_tje_nakun_i_lilan_sulan_mi.

on_tree_still_have_one_two_fruit

There are still one or two pieces of fruit on the tree. (Li 李云兵 2000)

The semantic feature bundles are [-quantified][-increasing $][+$ similar $][-$ bounded] $[--$ future-oriented].

These three notions, namely Greater Degree, Continuation, and Decrement, all correlate to properties or states, with the predicate location occupied by adjectives or stative verbs. The remaining notion Supplement may indicate either action or property/state.

\subsection{Supplement}

Supplement means to add a parallel different action or description of property/state to the original one. It could be either future-oriented or not.

\section{(Hlai: Hlaic, Tai-Kadai)}

(25) tshat_gei_ hat_na:u_lom_ ha _owei.

buy_rice_buy_salt_again_buy_oil

(He) bought rice and salt and also bought oil. (Ouyang and Zheng 欧阳觉亚, 郑贻青 1980)

We could more specifically describe the notion as [-quantified][+increasing][-similar][+bounded][ \pm future-oriented].

Thus far, all the ten notions could be demonstrated within the following table (Table 1): 
Table 1 Semantic features of Repetition and related notions

\begin{tabular}{llllllll}
\hline & Quantified & Increasing & Similar & Bounded & Future-oriented & Sequenced & Category \\
\hline Increment & + & + & + & + & + & \pm & Action \\
Repetition & \pm & + & + & + & + & \pm & \\
Sequentiality & - & + & - & + & + & + & \\
Inverted Sequence & - & + & - & + & + & - & \\
Greater Degree & \pm & + & + & - & + & \pm & Property \\
Continuation & - & \pm & + & - & - & \pm & \\
Decrement & + & - & + & - & - & \pm & \\
Supplement & - & + & - & + & \pm & \pm & Action/property \\
\hline
\end{tabular}

By examining the eight different concepts from the same six parameters, all the concepts could be captured under a unified framework. One possible challenge to this approach is that mathematically speaking in order to differentiate eight items, three parameters are enough (as the third power of 2 is 8). However, the parameters we use, namely the six different semantic features, are descriptive rather than decisive. That is to say, all the parameters are necessary as they each unravel a certain aspect of the notion and there should be no doubt cast on the redundancy of the parameters.

When we compare the different aspects of each notion, we find that some of the notions share more semantic features whereas others might behave more differently as regards the six semantic features. For example, Sequentiality and Inverted Sequence share five semantic features out of six and the only bifurcation lies in that one entails a sequence in between two correlated actions whereas the other one does not. However, when we compare Sequentiality with the notion of Decrement, we find that they behave differently in all the six parameters and the sole similarity is that both of the notions could occur in a context where a sequence between two actions is introduced, although the feature of [sequenced] is mandatory for the notion of Sequentiality but optional for the notion of Decrement. The aforementioned are just two extreme examples in terms of the degrees of semantic similarity. In fact, if we randomly take two notions in the above table, the degree of the semantic similarity between the two could be quantified by the number of the semantic features they share. That is to say, if two notions share the same feature (both "+" or both "-" or both " \pm "), 1 point will be allotted; if the two notions behave the opposite on the same semantic feature (one "+" and the other " - "), -1 point will be allotted; and if one notion is neutral on the semantic feature (" \pm ") and the other is not ("+" or "-"), 0.5 point will be allotted. In this way, the semantic similarity among all the possible pairs of notions could be measured by a number (Table 2).

The semantic similarity derived from pure semantic analysis is certainly helpful in deducing the conceptual correlations of the notions. As suggested in Zwarts (2010: 377), the more similar the two notions, the more likely they are to have conceptual correlations. Zwarts (ibid: 388) further points out a working principle in defining conceptual connections through semantic feature analysis: "an arc is drawn between meanings that differ only in one feature (roughly speaking)". This one-feature difference pattern could undoubtedly guarantee the contiguity of the two meanings. However, in real investigations, concepts do not always differ exactly as imagined in this suggested pattern. In fact, we only need to find out the pair of notions that share relatively the most semantic 
Table 2 Semantic similarities among pairs of notions

\begin{tabular}{lllllllll}
\hline & INC $^{6}$ & REP & SEQ & I-S & G-D & CON & DEC & SUP \\
\hline INC & - & - & - & - & - & - & - & - \\
REP & 5.5 & - & - & - & - & - & - & - \\
SEQ & 1.5 & 3 & - & - & - & - & - & - \\
I-S & 1.5 & 3 & 4 & - & - & - & - & - \\
G-D & 3.5 & 4 & 1 & 1 & - & - & - & - \\
CON & -0.5 & 1 & -1 & -1 & 3 & - & - & - \\
DEC & 0 & -0.5 & -4.5 & -4.5 & 1.5 & 3.5 & - & - \\
SUP & 1.5 & 3 & 5 & 5 & 1 & 1 & -2.5 & - \\
\hline
\end{tabular}

features. That is to say, the more similar pairs of notions should occupy more adjacent areas in the conceptual space than their counterparts. In light of this principle, we can start by first linking the pair of notions where the highest value 5.5 applies--"Increment-Repetition", and then the pair with the second highest value, "Sequence-Supplement-Inverted Sequence" and so on till we have worked out a network which involves all eight notions. It happens that the links in the following figure represent semantic similarity values no lower than 3 . A tentative conceptual space of repetitive adverbs developed by pure semantic analysis is shown below with the numbers indicating the semantic similarity values (Fig. 8).

As this approach is based on semantic analysis, it is widely termed as a "meaningdriven" approach. Its counterpart, known as the "data-driven" approach, will be discussed in the following two sections.

\section{Language data and schemas of the conceptual space on Repetition}

Apart from first-hand data from 40 languages that we have collected at UCLA and BLCU respectively, there are also 33 examples of second-hand data included to help to further reveal the conceptual relations expressed by the repetitive adverbs. As there are overlapping languages between the first-hand data and the second-hand data, the total data sources are from 69 languages. The following table offers a breakdown of all the data with the first-hand sources in bold and second-hand sources in italic. The overlapping ones are in bold and italic (Table 3).

For all the eight concepts that we have analyzed in the previous section, example sentences have been designed to help the interviewees to find the formal expression of that notion in

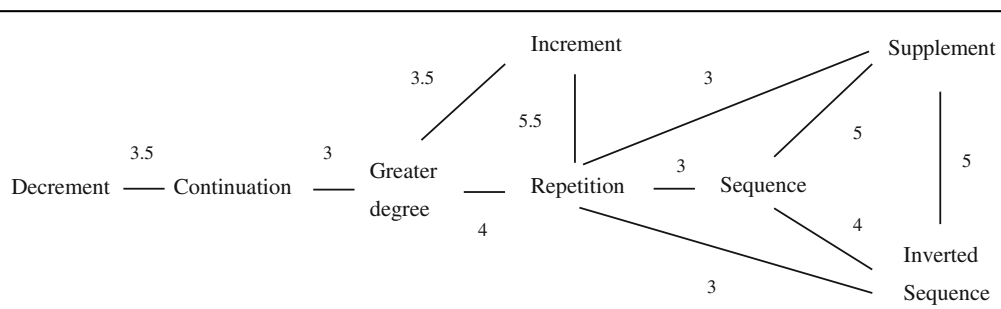

Fig. 8 Tentative conceptual space centered on Repetition 
Table 3 Data sources by language families and branches

\begin{tabular}{|c|c|c|}
\hline \multirow[t]{5}{*}{ Indo-European } & Balto-Slavic & Croatian, Czech, Latvian, Russian \\
\hline & Germanic & Antigua and Barbuda Creole English, English, German \\
\hline & Graeco-Phrygian & Greek \\
\hline & Indo-Iranian & Bengali, Hindi, Persian, Tajik, Urdu \\
\hline & Italic & French, Italian, Portuguese, Romanian, Spanish \\
\hline \multirow[t]{3}{*}{ Sino-Tibetan } & Sinitic & $\begin{array}{l}\text { Hakka (Liancheng, Zhongshan), Hui Chinese (Qimen), } \\
\text { Jin Chinese, Min Dong Chinese (Cangnan, Leizhou, Taishun), } \\
\text { Min Nan Chinese (Leizhou, Taipei, Yun'ao), Southwestern Guanhua } \\
\text { (Chongqing), Wu Chinese (Jinyun), Yue Chinese (Hong Kong) }\end{array}$ \\
\hline & Bodic & Tibetan \\
\hline & Burmo-Qiangic & Jinghpaw, Lahu, Naxi, Phola, Qiang, Sichuan Yi, Zauzou \\
\hline \multirow[t]{2}{*}{ Atlantic-Congo } & Volta-Congo & Ghomálá, Kinyarwanda, Shona, Swahili, Tswana \\
\hline & North-Central Atlantic & Pular \\
\hline Austronesian & Nuclear Austronesian & Indonesian, Malay, Saisiyat, Tagalog \\
\hline Turkic & Common Turkic & Kazakh, Turkish, Uzbek \\
\hline \multirow[t]{2}{*}{ Tungusic } & Northern Tungusic & Orogen \\
\hline & Manchu-Jurchen & Xibe \\
\hline \multirow[t]{3}{*}{ Tai-Kadai } & Kam-Tai & Dong, Mak, Thai, Zhuang \\
\hline & Hlaic & Hlai \\
\hline & Kadaic & Lachi \\
\hline Hmong-Mien & Hmongic & Hmong, Jiongnai, Yuno \\
\hline \multirow[t]{3}{*}{ Austroasiatic } & Vietic & Vietnamese \\
\hline & Khasi-Palaung & Awa \\
\hline & Palaungic & Bumang \\
\hline Afro-Asiatic & Semitic & Arabic \\
\hline Koreanic & & Korean \\
\hline Japonic & & Japanese \\
\hline
\end{tabular}

their mother tongue. Based on the data collected plus 33 more second-hand types of data, we set up a conceptual space centering on the notion of Repetition as follows (Fig. 9).

The definition and analysis of the eight notions show that all four of the notions within the domain of "action", namely Increment, Repetition, Sequentiality, and Inverted Sequence, are all located at the bottom right-hand side of the map, and those in the domain of "property", namely Decrement, Continuation, and Greater Degree, are all located at the upper left-hand side. The notion in between these domains, such as Supplement could refer to both domains. See Fig. 10 for an illustration of these findings (Fig. 10).

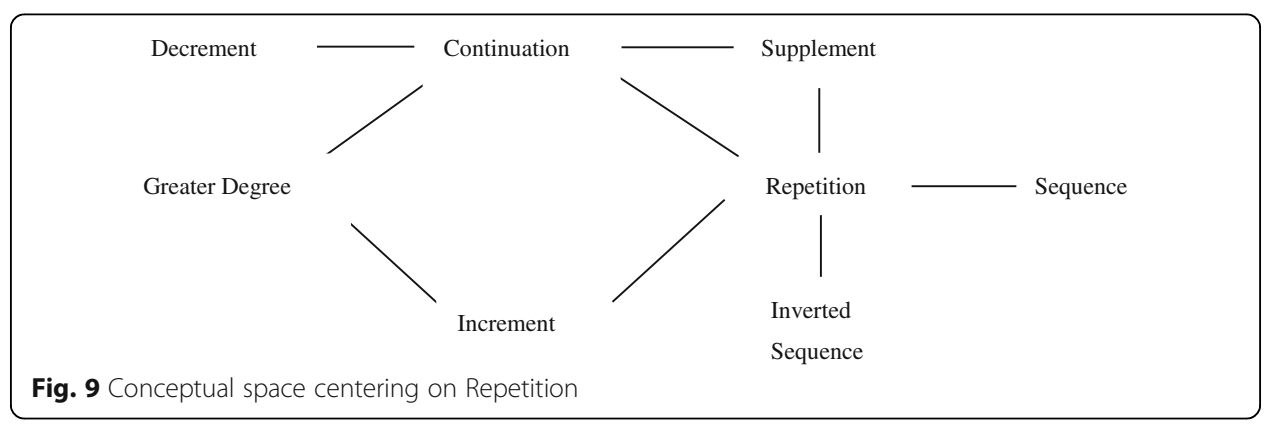




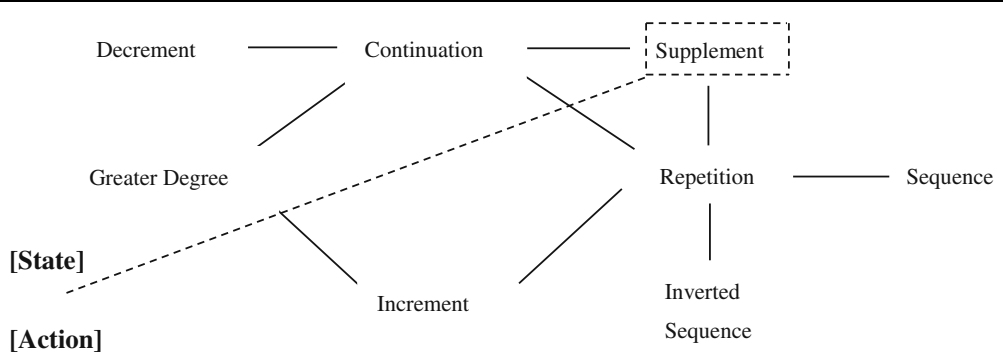

Fig. 10 Zoning of the conceptual space centering on the notion of Repetition

This verifies the hypothesis that those notions located closer to each other in a conceptual space have a closer semantic relationship. The following section offers two sub-maps of the original conceptual space according to the zoning pattern shown above and analyzes them respectively by presenting the cross-linguistic data.

\subsection{Sub-map A of the conceptual space of Repetition}

Sub-map A involves the notions that belong to the domain of "action", and the relation between sub-map A and the overall semantic map is as follows (Fig. 11):

In the following table, we offer a breakdown of the cross-linguistic data that proves the connecting pattern shown in the dotted box. The data includes those from both first-hand and second-hand sources and is differentiated in bold and italics, respectively, (data involving the five notions in the dotted box but not limited to these notions will be discussed after the introductions of the two sub-maps) (Table 4).

The double-functional grams shown as types 1, 2, and 3 in the above table demonstrated the direct connection between the notion of Repetition and the notions of Increment, Supplement, and Inverted Sequence, respectively. For example:

\section{Repetition-Increment}

\section{(Min Dong Chinese [Cangnan]: Chinese, Sino-Tibetan)}

(26) 请你讲(一)遍添。

$$
\begin{aligned}
& \text { t6 }{ }^{\mathrm{h}} \mathrm{iã} \_\mathrm{n} \_\mathrm{kõ} \_\mathrm{p} \tilde{1} \_\mathbf{t}^{\mathbf{h}} \tilde{\mathbf{i}} \text {. } \\
& \text { please_2SG_say_(one)time_again }
\end{aligned}
$$

Please say [it] one time again.

(27) 你吃一碗添。

$$
\text { n__zi_(iə?) vẽ_t } \mathbf{t}^{\mathbf{h}} \tilde{\text {. }}
$$

2SG_eat_(one) bowl_more

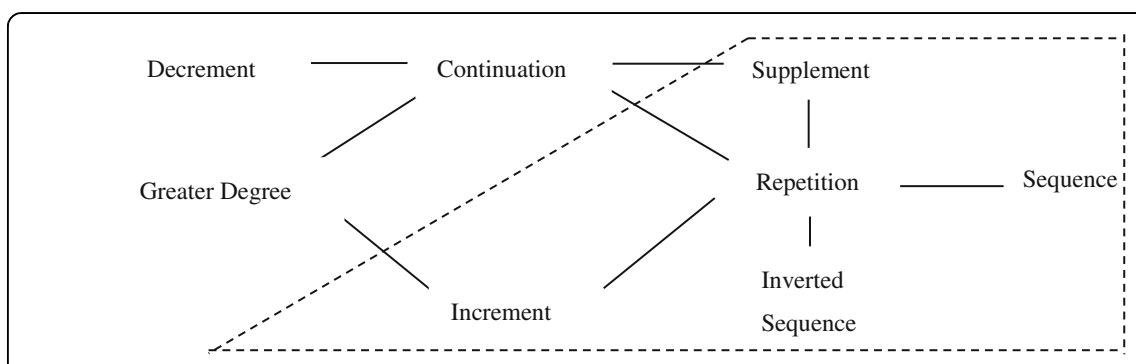

Fig. 11 Sub-map A of the original conceptual space on Repetition 
Table 4 Language data for sub-map A of the conceptual space centered on Repetition

\begin{tabular}{|c|c|c|c|c|c|c|}
\hline & & REP & INC & SUP & I-S & SE \\
\hline 1 & $\begin{array}{l}\text { Arabic: akhar; Hui Chinese (Qimen): 湊 ts }{ }^{\mathrm{h}} \text {; Japanese: mou; Kinyawanda: } \\
\text { indi; Malay: lagi; Min Dong Chinese (Cangnan): 添 } \mathrm{t}^{\mathrm{h}} \text {; Min Nan Chinese (Yun'ao): } \\
\text { 加 ke; Southwestern Guanhua (Chongqing): 又 iəu; Wu Chinese (Jinyun): 添 } \mathrm{t}^{\mathrm{h}} \mathrm{ie} ; \\
\text { Korean: tto }\end{array}$ & + & + & & & \\
\hline 2 & Croatian: i; Hlai: lom; Dong: yuh; Russian: e'piæt;; Swahili: pia; Awa: bau; Yuno: zou & + & & + & & \\
\hline 3 & $\begin{array}{l}\text { Bengali: abar; Creole: again; Czech: zhovu; French: de novo; German: wieder; } \\
\text { Hindi: phirse; Italian: di nuovo; Kinyawanda: nanont; Korean: dasi; Persian: } \\
\text { do baareh; Portuguese: de novo; Russian: snova; Tswana: gape; Shona: zvekare; } \\
\text { Spanish: otravez; Swahili: tena; Tagalog: ulit; Turkish: tekrar }\end{array}$ & + & & & + & \\
\hline 4 & Tajik: bo; Urdu: or; Vietnamese: thêm & + & + & + & & \\
\hline 5 & $\begin{array}{l}\text { Southwestern Guanhua (Chongqing): 再 tsai; Thai: i:k?; Sichuan Yi: si; } \\
\text { Zhuang: youh }\end{array}$ & + & + & & + & \\
\hline 6 & Hakka (Liancheng): 添 $\mathrm{t}^{\mathrm{h}} \mathrm{a}$; Lahu: qo & + & + & & & + \\
\hline 7 & Naxi: le & + & & + & + & \\
\hline 8 & Jinghpaw: bai; Pular: kadhi; Tibetan: yang; Uzbek: yana & + & + & + & + & \\
\hline 9 & Indonesian: lagi; Zhuang: caiq & + & + & & + & + \\
\hline 10 & Kazakh: tagi & + & + & + & + & + \\
\hline
\end{tabular}

Please eat (one) more bowl of rice. (Akitani 秋谷裕幸 2005)

\section{Repetition-Supplement}

(Hlai: Hlaic, Tai-Kadai)

(28) lom_ han___ _ ka:i.

again_sing_one_time

Sing (it) one more time.

(29)ha__gei_ ha _ a:u_lom_ ha _owei.

buy_rice_buy_salt_also_buy_oil

(He) buys rice, salt and also oil. (Ouyang and Zheng 欧阳觉亚, 郑贻青 1980)

\section{Repetition-Inverted Sequence}

(German: Germanic, Indo-European)

(30) Morgen_ist_schon_wieder__Sonntag! tomorrow_is_already_again__Sunday

It's Sunday tomorrow again!

(31) Als_sie_starben, sahen_sie_wieder_einmal_jung_aus.

When_they_die, appear_they_again_once_young_PREF

When they were dying, they look young again.

So far, there is only one link in sub-map A that has not been discussed yet--the link between Repetition and Sequentiality. Although there is no double-functional data that could directly prove the affinity between this pair of notions, the multi-functional data suggests that the connection between Sequentiality and Repetition is a prerequisite to realize the "semantic connectivity hypothesis (SCH)". Data type 6 is one of these cases, which involves the notions of Increment, Repetition, and also Sequentiality. 


\section{Sequence-Repetition-Increment}

\section{(Lahu: Burmo-Qiangic, Sino-Tibetan)}

(32)这会儿我上课;等一下再谈。

tshi_tekhu_na_li_mase_a,

a_mu_te_khm_qo_qu_da_a.

this_moment_1SG_book_teach_AUX,

wait_a moment_then_talk_RECP_AUX

I am teaching at the moment; wait for a moment and then I will talk to you.

(33) 请你明天再来吧。

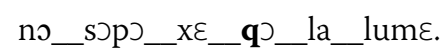

2SG_tomorrow_AUX_again_come_AUX

You may come again tomorrow.

(34)如果今年盖好校舍,明年就再招两班学生。

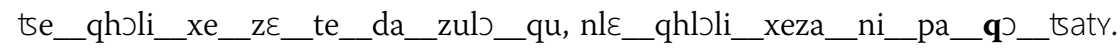

this_year_school_built_finish_if_SFP,

next_year_student_two_classes_more_enroll

If the construction of the school building could be finished this year, then next year two more classes could be enrolled. (Chang 常宏恩 1986)

Other multifunctional grams that contain the notion of Repetition include caiq in Zhuang and also tagi in Kazakh. Both of them have verified the validity of the connection between Repetition and Sequentiality. ${ }^{7}$ The representation patterns of the above data could be illustrated as below (Fig. 12).

All these data could occupy a contiguous area in sub-map A, including the remaining four types of data 4, 5, 7, and 8 (Fig. 13).

\subsection{Sub-map B of the conceptual space centered on Repetition}

The relation between sub-map B and the overall semantic map is as follows (Fig. 14):

As stated in the zoning of the original conceptual space, the four concepts in submap B--Continuation, Supplement, Decrement, and Greater Degree are more likely to be associated with descriptions of state/property. The following is the list of data by which sub-map B is established (Table 5).

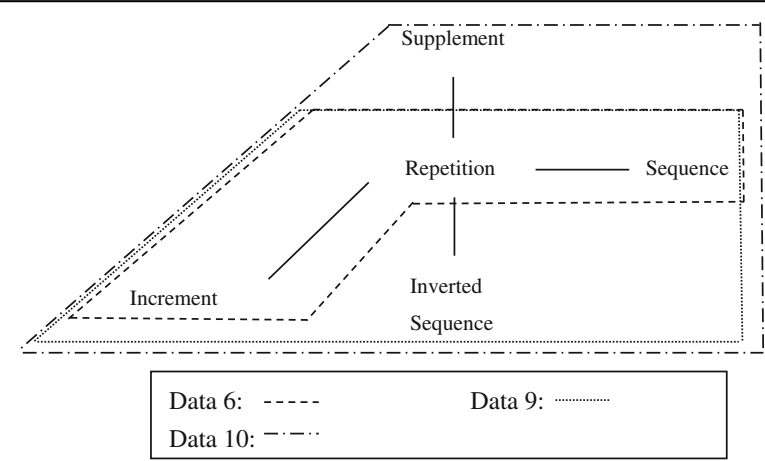

Fig. 12 The representations of data types 6, 9, and 10 for sub-map A 


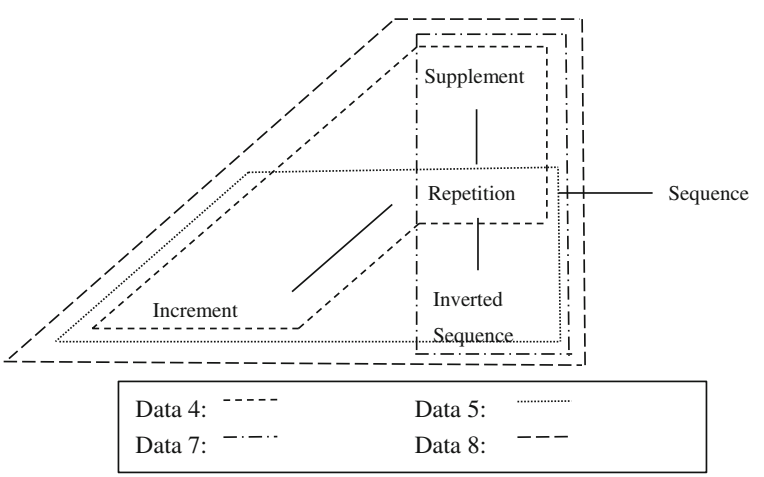

Fig. 13 The representations of data types4, 5, 7, and 8 for sub-map A

All the three links that have appeared in sub-map B, namely the "Continuation-Supplement," "Continuation-Decrement", and "Continuation-Greater Degree", have been directly verified by the three types of double-functional grams shown above as data types 11,12 , and 13 , respectively.

\section{Continuation-Supplement}

(Min Nan Chinese [Leizhou]: Sinitic, Sino-Tibetan)

(35)伊也无讲了 $\square \square$ ? $^{8}$

$$
\begin{aligned}
& \text { i_ia_bo_ko_liau_tu_e? } \\
& \text { 3SG_still_NEG_speak_PFV_SFP } \\
& \text { Hasn't he finished his speaking yet? }
\end{aligned}
$$

(36) 你也会讲也也无嘞?

$$
\text { lu_ia_oi_ko_mimi_bo_le? }
$$

2SG_also_can_say_INDF_NEG_SFP

Can you also say something else or not? (Lin 林伦伦 2006)

\section{Continuation-Decrement}

\section{(Portuguese: Italic, Indo-European)}

(37) Quando_ele_ligou, eu_ainda_está_tomando_banho. when_3SG_call.PST, 1SG_still_COP_take.PROG_bath

When he called, I was still taking a bath.

(38) Eu_ainda_tenho_algum_dinheiro_sobrando.

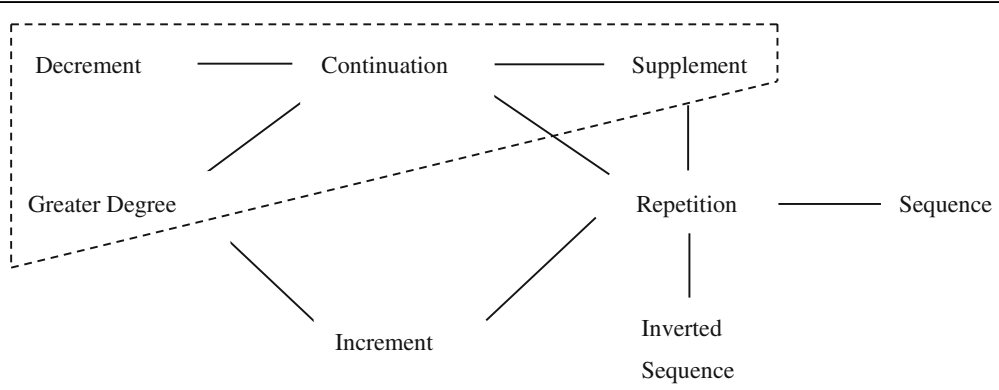

Fig. 14 Sub-map B of the original conceptual space on Repetition 
Table 5 Language data for sub-map B of the conceptual space centered on Repetition

\begin{tabular}{|c|c|c|c|c|c|}
\hline & & CON & SUP & DEC & GRE-D \\
\hline 11 & Hmong: sat; Min Nan Chinese (Leizhou): 也 ia & + & + & & \\
\hline 12 & $\begin{array}{l}\text { Arabic: la yazal; Bengali: akhono; Hindi: abhi; Kazakh: alide; } \\
\text { Kinyarwanda: ayari; Korean: ajik; Portuguese: ainda; Tajik: holoham; } \\
\text { Turkish: hâla; Urdu: abhibi; Uzbek: holoyam }\end{array}$ & + & & + & \\
\hline 13 & Japanese: nao & + & & & + \\
\hline 14 & $\begin{array}{l}\text { Lachi: nakun; Mak: nan; Min Dong Chinese (Cangnan): 還 } \\
\text { a; Min Dong Chinese (Taishun): 故 ku; Zhuang: lij }\end{array}$ & + & + & + & \\
\hline 15 & $\begin{array}{l}\text { Creole: til; Ghomálá: jabu; Indonesian: masih; Malay: masih; } \\
\text { Persian: hanooz; Pula: ha djioni } \\
\text { Shona: -chiri; Spanish: todavia; Swahili: bado } \\
\text { Thai: yang; Vietnamese: vâncòn }\end{array}$ & + & & + & + \\
\hline 16 & Min Nan Chinese (Yun'ao): 還 hã; Sichuan Yi: yip si & + & + & + & + \\
\hline \multicolumn{6}{|c|}{$\begin{array}{l}\text { 1SG_still__have_some_money_left } \\
\text { I still have some money left. }\end{array}$} \\
\hline \multicolumn{6}{|c|}{$\begin{array}{l}\text { Continuation-Greater Degree } \\
\text { (Japanese: Japonic) }\end{array}$} \\
\hline \multicolumn{6}{|c|}{$\begin{array}{l}\text { (39) Sono__densetu_wa_ima_nao__imotonohito__ni_kataritugareteiru. } \\
\text { that_legend__TOP_now__still__native__PASS_transmit } \\
\text { Now that legend is still transmitted by the natives. } \\
\text { (40) kimi_ga_kitekurereba_nao_ii }\end{array}$} \\
\hline
\end{tabular}

When we compare the sources of data types 11,12 , and 13, we notice that data supporting the connection between Continuation and Decrement far outnumber its counterparts. It demonstrates that the correlation between some of the notions might be much closer than that between other pairs. This affinity between Continuation and Decrement has also been verified by the rest of the data concerning sub-map B. We could regard data type 14 as grams expressing CON and DEC that take over the meaning of SUP, and data type 15 as taking over the meaning of G-D, whereas data type 16 extends to both meanings. All of the three types of data demonstrate the closeness between CON and DEC.

\section{Continuation-Decrement-Supplement}

\section{(Lachi: Kadaic, Tai-Kadai)}

(41)a qui_nakun_pha wind_still_blow

The wind is still blowing.

(42) ua_mtje__nakun_i_lilan_sulan__mi.

LOC_tree_still_have_one_two_fruit

There are still one or two pieces of fruit on the tree.

(43) ki_ahuan_6u_kje_ano__kja, nakun_hje_tjou_o_a no__sei_kje. 
1SG_not only_know_3SG_surname_INDF, also_say_COMP_C_given name_3SG

I not only know his surname, but also can say his given name. (Li 李云兵 2000)

\section{Continuation-Decrement-Greater Degree}

(Thai: Kam-Tai, Tai-Kadai)

(44) tawn-thii_khao_tho-ma, pho:m_ya:ng_aab-naam_yuu when_3SG_call, 1SG_still_shower_SFP

When he called, I was still taking a shower.

(45)ya:ng_mii_(pho:nlamai)luea_yuu_bo:n_to:n_sa:k_luuk-2_luuk still_there (fruits) _left_be_LOC_tree_about_CLF-2_CLF

There are still about one or two pieces of fruit left one the tree.

(46) thaang_ta:wa:n-awk_kaw-ya:ng_naaw-kwaa.

side_east_still_cold-CM.

It is still colder on the east side.

\section{Continuation-Supplement-Decrement-Greater Degree}

(Sichuan Yi: Burmo-Qiangic, Sino-Tibetan)

(47) diep_ddop_ndup_te_go, cy_yyrx_cy_njuo_yip si.

telephone_call_when, 3SG_shower_PROG_still

When the phone was ringing, he was still taking a shower.

(48) nga_syp_hni, syp_ndat, yip si_xie_jo_nyi_vy_ox.

1SG_apple_pear_also_banana_NOM_buy_SFP

I bought apples, pears, and also bananas.

(49) syr_bbo_go_syp_hni_nyip_ma_go_ndit_yip si.

tree_LOC_apple_two_have_still

There are still two apples on the tree.

(50) ha lyr bi_li_bip ji_jox ap cy mu_mgo_yip si.

Haerbin_Beijing_CM_cold_still

Haerbin is still colder than Beijing.

Thus, the above three types of data from 14 to 16 could be demonstrated as follows (Fig. 15).

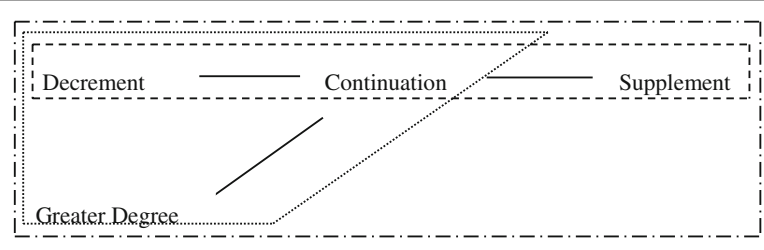

Data 14: -..- Data 15:

Data 16: $-\cdot-\cdot$

Fig. 15 The representations of data types 14 to 16 for sub-map B 
So far, we have reviewed all the data that relate to the semantic connections shown in sub-map A and sub-map B respectively. However, there are still some semantic links which involve notions in both maps like the link between "Continuation-Repetition" and "Increment-Greater Degree" on the original conceptual space that have not been taken care of yet. Therefore, more data will be introduced in the following section to illustrate the semantic links involving both sub-maps.

\subsection{Data connecting sub-map A and sub-map B}

There are two bridges that connect the two sub-maps together: the first one is the link of "Increment-Greater Degree," and the second one is "Repetition-Continuation." Increment and Repetition belong to the domain of "action" (sub-map A) whereas Greater Degree and Continuation belong to the domain of "property" (sub-map B).

The following data shows the direct connection between Increment and Greater Degree (Table 6).

There are data which could directly suggest the connection between INC and G-D, and daha in Turkish is one of these cases.

\section{Increment-Greater Degree}

(Turkish: Common Turkic, Turkic)

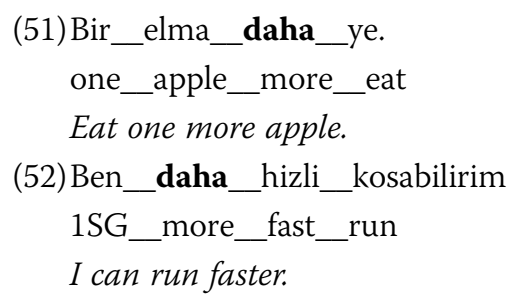

Expressions for these two notions could also extend their uses to other notions in the action domain, like zoi in Yue Chinese. Apart from INC and G-D, it can also express REP and SE. Data of types 17 to 19 could be illustrated in the following graph (Fig. 16).

Similarly, grams which could deliver the meaning of INC and G-D could also express other functions in the property domain, like $v e \bar{l}$ in Latvian (data type 22) which could express INC, G-D, SUP, CON, and DEC. Data of types 20 to 22 could be represented as follows (Fig. 17).

All the data from types 17 to 22 entail a semantic connection between INC and G-D. In fact, when examining the semantic features of INC and G-D, we find that it is not

Table 6 Language data involving INC-G-D

\begin{tabular}{|c|c|c|c|c|c|c|c|c|c|}
\hline & & INC & G-D & REP & SE & SUP & I-S & CON & DEC \\
\hline 17 & Korean: deo; Portuguese: mais; Spanish: mas; Turkish: daha & + & + & & & & & & \\
\hline 18 & Bengali: aro; Hindi: aur & + & + & + & & & & & \\
\hline 19 & Yue Chinese: zoi & + & + & + & + & & & & \\
\hline 20 & Ghomálá: bing & + & + & + & & + & + & & \\
\hline 21 & Greek: akoma; Tswana: santse; Tagalog: pa & + & + & & & & & + & + \\
\hline 22 & Latvian: vēl & + & + & & & + & & + & + \\
\hline
\end{tabular}




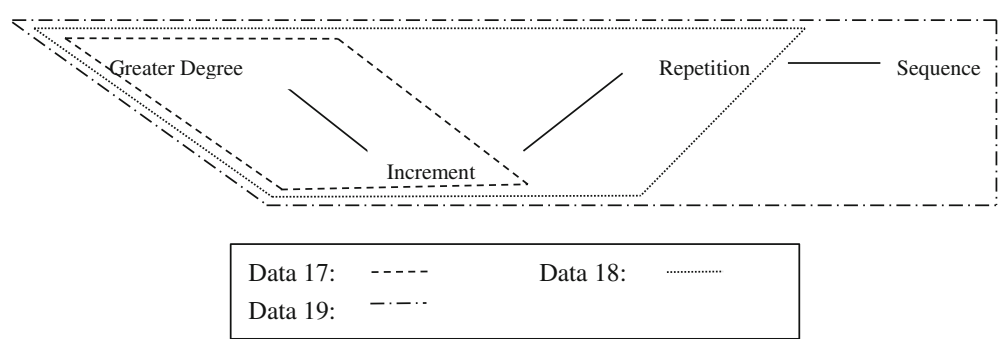

Fig. 16 The representations of data types 17 to 19

uncommon to find correlations between these two notions. Among the three notions that belong to the domain of property, G-D shares the most semantic features with INC. To be specific, they only differ in one parameter--"boundedness." That is to say, INC requires the object in scope to be bounded whereas G-D does not. By contrast, the two other alternative members in the domain of property both diverse with INC on more than three parameters. This intrinsic semantic analysis also demonstrates the validity of the connection between INC and G-D.

Another bridge that connects the two sub-maps is the link of REP-CON. Data that suggests the correlation between these two notions are presented in the following table (Table 7).

Similarly, we have double-functional grams which could only express the meanings of REP and CON.

\section{Repetition-Continuation}

\section{(Xibe: Manchu-Jurchen, Tungusic)}

(53)Şi_ər_əm_dziashanb_hualəm_tatəmaq,

kəmuni_udlzudləri_arəm_dəriv .

2SG_this_one_letter_tear_C, again_begin_write_start

You tear up this letter, and start to write again from the beginning.

(54) tər_tə__kəmuni_morin_aqu.

3SG_now_still_horse_NEG

He hasn't had a horse yet. (Li and Zhong 李树兰, 仲谦 1986)

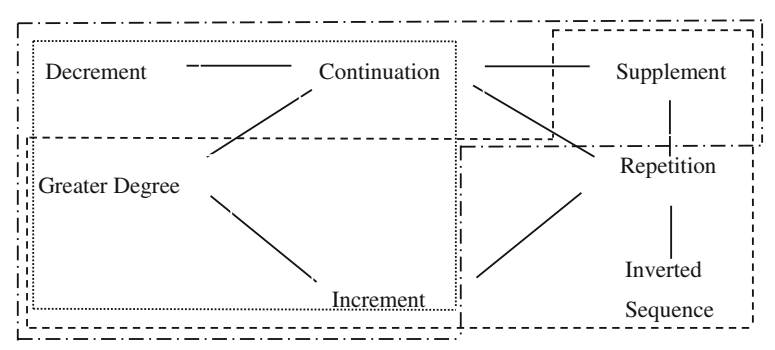

Data 20: --.- Data 21: ……......

Data 22: - -...

Fig. 17 The representations of data types 20 to 22 


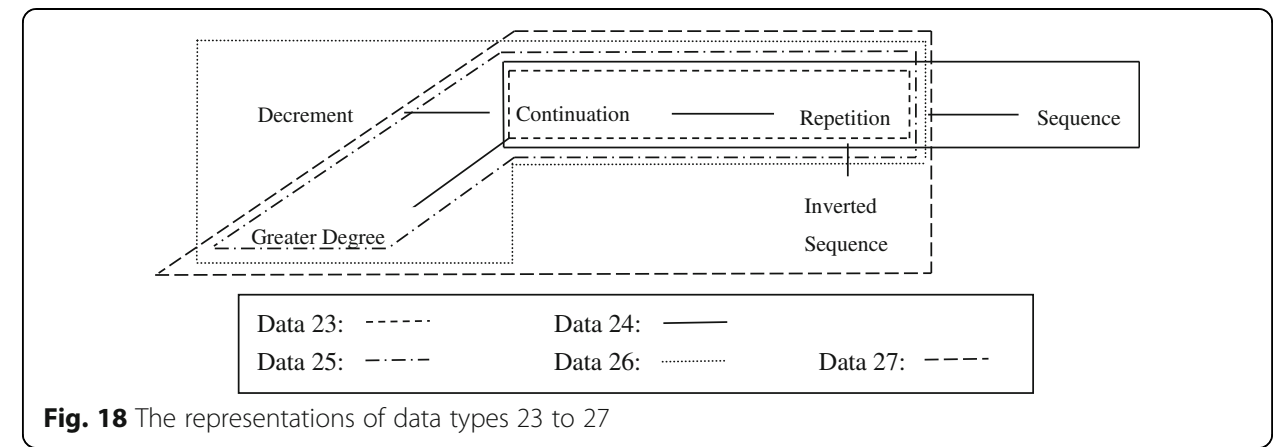

Apart from the double-functional data, there are also grams which contain but are not limited to these two notions. Data of type 24 shows that grams expressing CON and REP could also take over the function which belongs to the action domain like SE. Besides, grams expressing CON and REP could also take the meaning of G-D which belongs to the domain of property.

The data that entails the connection of REP and CON could be diagrammed as below (Fig. 18):

All the data from types 23 to 27 have demonstrated the necessity of linking the notion of CON and REP, as the functions expressed by these data would not occupy a contiguous area unless the two nodes are connected. Once connected, these two nodes plus the node of SUP would constitute a triangle in the original conceptual space. In fact, there are a variety of multifunctional grams demonstrating the affinity of these three nodes that we have not yet discussed (Table 8).

Data types 28 to 31 could be represented in the following diagram (Fig. 19).

Multifunctional grams expressing these three functions may also extend the uses to SEQ and I-S.

\section{Repetition-Supplement-Continuation-Sequence-Inverted Sequence (Saisiyat: Nuclear Austronesian, Austronesian)}

(55) Senge-en_nahan_ray_ralom_a $=$ _talek-

en_ma'_nak_isaa_ma_kin_kayzaeh si'ael-en.

soak-pf_again_loc_water_fil_heat-

pf_also_like_that_dm_very good_eat-pf

Soak them again in water, and they would taste better if heated.

(56)KoSa'-en_kasaklay_bangol_ka=wa'ae'_ 'aehae_nahan_sinkano'on say-pf_field_forest_nom deer_bc_another_what

Table 7 Language data involving REP-CON

\begin{tabular}{|c|c|c|c|c|c|c|c|c|c|}
\hline & & INC & G-D & REP & SE & SUP & I-S & CON & DEC \\
\hline 23 & Romanian: înca; Xibe: kəmuni & & & + & & & & + & \\
\hline 24 & Dong: siip; Oroqen: dakI & & & + & + & & & + & \\
\hline 25 & Croatian: joș, Italian: ancora & & + & + & & & & + & \\
\hline 26 & Japanese: mata & & + & + & & & & + & + \\
\hline 27 & Yue Chinese: faan & & + & + & & & + & + & \\
\hline
\end{tabular}


Table 8 Language data involving REP-CON-SUP

\begin{tabular}{|c|c|c|c|c|c|c|c|c|c|}
\hline & & INC & G-D & REP & SE & SUP & I-S & CON & DEC \\
\hline 28 & Bumang: $\mid \varepsilon ;$ Orogen: mətər & & & + & & + & & + & \\
\hline 29 & Jiongnai: גan; Yuno: nan; Zauzou: tse & & & + & & + & & + & + \\
\hline 30 & Qiang: pi; Romanian: mai & & + & + & & + & & + & \\
\hline 31 & Phola: tam & & & + & + & + & & + & \\
\hline 32 & Saisiyat: nahan & & & + & + & + & + & + & \\
\hline 33 & Southwestern Guanhua (Chongqing): 還 hai & & + & + & & + & + & + & + \\
\hline 34 & $\begin{array}{l}\text { Yue Chinese: 仲 zung; Czech: jěstě } \\
\text { Jinghpaw: no; Min Nan Chinese (Taipei): 再 ko?; } \\
\text { Russian: eshcho; Tibetan: tarong }\end{array}$ & + & + & + & & + & & + & + \\
\hline
\end{tabular}

There is one kind (called field deer); hey, there is another whatchamacallit.

(57) Isaza_tatini'_rima' $r<$ om $>$ okrok_nahan_babaw_ka_boway.

that_old.man_af.go <af $>$ pick_still_above_acc_fruit

The old man was still up in the tree to pick fruit.

(58) M-wa:i__kabih_nahan_langi_'akoy'_atomalan_ila_kita-en_ka_a_takem. come_aside_first_shore_many_very_pfv_see-pf_nom_lnk_frog

They came first to the shore, and saw many frogs.

(59)M-olaw_kita'-en__ma'_al'alak_ila_nahan

af-molt_see- pf_also__young__pfv_again

(When they were dying,) they molted and looked young again (Huang 2007).

There are other multifunctional data expressing six notions in the original conceptual space which could also demonstrate the affinity among the notions of REP, SUP, and CON.

\section{Repetition-Supplement-Continuation-Increment-Decrement-Greater Degree (Yue Chinese [Hong Kong]: Sinitic, Sino-Tibetan)}

(60)呢出戲仲要睇多次。

$$
\text { ne_ceot_hei_zung_jiu_tai_do_ci }
$$

That show (I) want to watch one more time.

(61) (我尋日唔止打咗波,)仲遊咗水添。

$$
\begin{aligned}
& \text { (ngo_camjat_m_zi_daa_zo_bo,) zung_jau_zo_seoi_tim } \\
& \text { ISG_yesterday_not_only_play_PFV__ball, }
\end{aligned}
$$

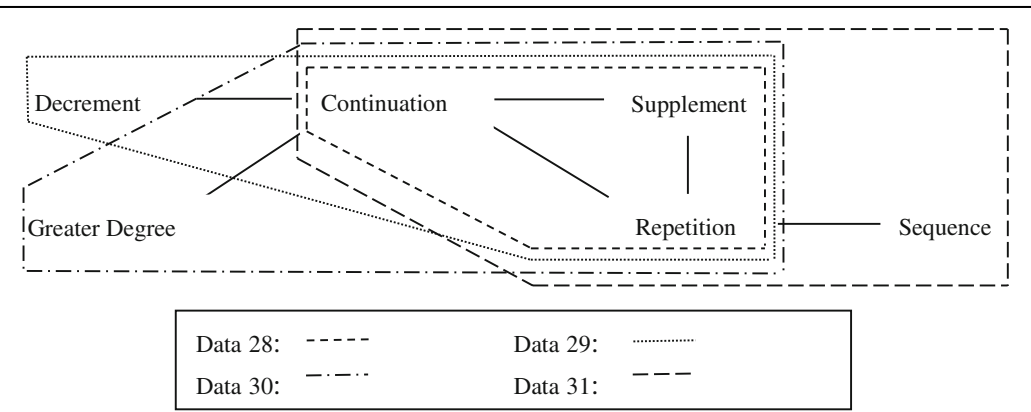

Fig. 19 The representations of data types 28 to 31 
also_swim_PFV_water__SFP

Yesterday, I not only played ball, but also swam as well.

(62) (天都黑喇,)鄧老師仲系度做緊嘢。

tin_dou_haak_laa, dang_lousi_zung_hai_dok_zou_gan_je

sky_already_dark_SFP, Dang_teacher_still_there_do_

PROG_thing

(It is getting dark,) but Professor Dang is still there doing stuff.

(63)琴日我食咗三個蘋果,今日仲要食五個。

kamjat_ngo_sik_zo_saam_go_pangwo,

gamjat_zung_jiu_sik_ng_go

yesterday_1SG_eat_PFV_three_CLF_apple,

today_also_want_eat_five_CLF

I ate three apples yesterday, and I want to eat five more today.

(64) 仲有十分鐘。

zung_jau_sap_fanzung

still_have_ten_minute

There is still ten minutes left.

(65) 東北仲凍過北京。

dungbak_zung_dung_gwo_bakging

Dongbei_even_cold_CM_Beijing

The northeast is even colder than Beijing.

Data types 32 to 34, which include the above multifunctional grams in Saisiyat and Yue Chinese, could be diagramed as follows (Fig. 20).

So far, all 34 types of data have been verified and all demonstrate the validity of the original conceptual space centering on Repetition as shown in Fig. 9.

\section{Revisiting the issues on Chinese repetitive adverbs}

The conceptual space discussed in the preceding section not only provides us the universal connective pattern of the related notions but can also shed light on some long-standing issues in the study of individual languages. This section attempts to show how we apply the cross-linguistic perspective to solve some outstanding problems

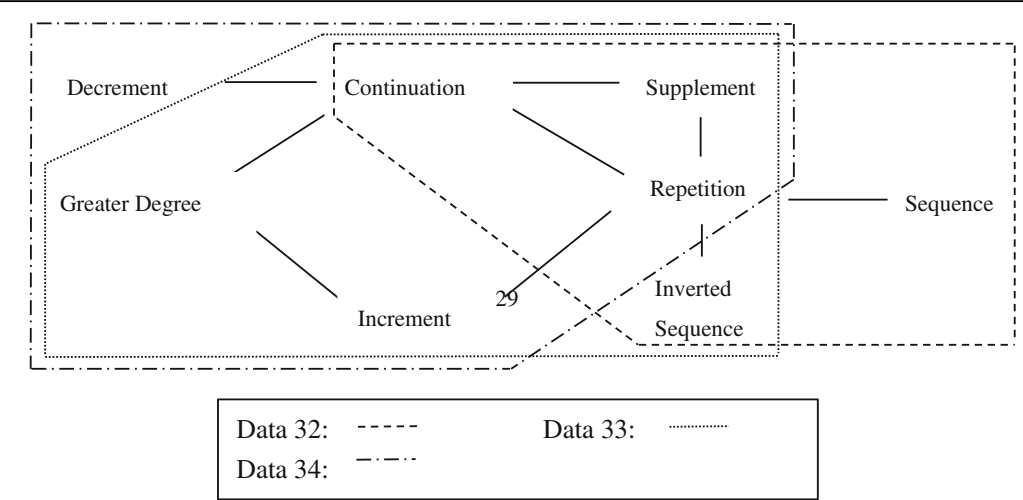

Fig. 20 The representations of data types 32 to 34 
concerning repetitive adverbs hai in Chinese. In so doing, we will demonstrate the advantage of cross-linguistic perspectives over monolingual ones.

Due to the high degree of polysemy of Chinese hai, characterizing its usage has long been a subject of dispute (literature on this issue has been mentioned in the introduction part). Clearly, it will take us too far afield to review every study here, but it is possible to introduce two representative studies which take the "abstractionist" position and the "polysemist" position, respectively.

In dealing with the many functions subsumed under one form, lexical semanticists, as suggested by Sweetser (1986: 528) and Haspelmath (2003: 212), can choose from two alternative positions: the "abstractionist" (or "monosemist" in Haspelmath's terms) position and the "polysemist" position. The "abstractionist" approach considers that the lexical item in question has "a single, highly abstract sense, which is simply broad enough in meaning to apply to many different surface referents, or which happens to have many different pragmatically predictable uses" (Sweetser 1986: 528). By contrast, the "polysemist" approach regards the multiple functions as "related but distinct senses," and "often there is an observatory direction to the relationship between these senses, one being more central than, or prior to, others (Sweetser 1986: 528)".

The "abstractionist" approach is quite popular among semantic analyses on hai, as it may lead to a unified interpretation to the scattered different senses attached to a form. Liu (2000) first attempted to apply the scalar model to relate the various functions of hai. ${ }^{9}$ Based on the scalar model proposed by Fillmore et al. (1988), the study argues that all the various functions expressed by hai could be subsumed to the scalar nature of hai. Specifically speaking, sentences with hai always associate with a stronger and more informative proposition in a scalar model compared to those without it. The study explains the functions of Continuation, Repetition, Supplement, Greater Degree, Moderately and Scalar Trigger expressed by hai via one persistent scalar model.

However, we believe "be informative" is presumably applicable to all scalar particles rather than a special property of hai per se. As stated in Liu (2000), the temporal use of hai constitutes a sharp contrast between the implicatures produced with hai and without hai. For example, 老王八點還在睡覺 laowang badian hai zai shuijiao 'Laowang is still asleep at 8 o'clock', the sentence without hai only suggests the proposition that "Laowang is asleep at 8 o'clock". By contrast, the sentence with hai will produce the same proposition as well as another entailment that "Laowang is asleep at times that are earlier than 8 o'clock". However, the informativeness is not a special property of hai per se but is an intrinsic requirement of any words that could trigger a scalar interpretation. For instance, the restrictive adverb only also has the scalar use. The sentence "he can only lift a box weighing $5 \mathrm{~kg}$ " could produce the proposition that "he can lift a box weighing $5 \mathrm{~kg}$ " as well as an entailment that "he can lift a box that weighs less than $5 \mathrm{~kg}$ ". In this sense, the abstract generalization that hai is always associated with more informativity is too broad to capture the uniqueness of hai.

In what follows, we will turn to the other extreme practice in dealing with the characterization of hai in Chinese. Instead of identifying a generalization abstract enough to cover every possible use of hai, there is an opposite approach that attempts to split the multiple meanings into more specific uses according to different contexts. One such example is Guo 郭锐 (2008), which identifies 18 different uses of hai. In Section 1, we have introduced his analysis on the concepts of Repetition and Inverted 
Sequence covered by hai. Following the same approach, Guo also identifies 16 other uses of hai, such as “延续 yanshu 'continuation”, “减量 jianliang 'decrement”, “计划不 变 jihua bubian 'retention of plan”, “条件 tiaojian 'condition”, “保持底线 baochi dixian 'bottom line”, “基本满意 jiben manyi 'basic satisfaction”, “不合理/不寻常 bu heli/ bu xunchang 'extraordinariness", “意外 yiwai 'out of expectation”, “原状态中止 yuan zhuangtai zhongzhi 'termination'”, “补充 buchong 'supplement”, “尚且 shangqie 'even”, and “待执行 dai zhixing 'to be performed”".

For some of the notions mentioned above, like "extraordinariness" and "out of expectation", it is very hard to identify the nuances through the proposed semantic structure. For example, the notion of "extraordinariness" and the notion of "out of expectation" are analyzed as following:

\section{Extraordinariness}

Semantic element: Situation E

Semantic relation: Situation E is abnormal or extraordinary (Guo 郭锐 2008: 10)

\section{Out of expectation}

Semantic element: Situation E

Semantic relation: Situation E is unexpected to the speaker or to the listener (Guo 郭

锐 2008: 10)

From the above illustration, it is still unclear how we can differentiate "extraordinariness" from "out of expectation" as the semantic structure analysis does not provide further information about these two notions. In fact, there is a natural connection between these two notions and I doubt that there is any language that could employ different formal devices to express these two meanings.

As mentioned earlier in the introduction, semantic analysis of polysemous words largely depends on the introspective inquiry of the researcher. When semanticists apply the "polysemist" approach to analyze the different uses of a polysemous word, the most challenging job is how to decide whether two uses should be combined as one function or not.

By reviewing the most typical works on the semantics of hai, one following the abstract approach (Liu 2000) and the other following the polysemy approach (Guo 郭锐 2008), we have explicitly unraveled the disadvantages of the monolingual perspective in dealing with the many-to-one mapping from function to form. In the following part, we will introduce how the cross-linguistic perspective can help us avoid this dilemma.

In fact, the reason accounts for the complexity of hai's categorizing is the difficulty of differentiating the "sense" and the "use" of hai. For a lexical item, "sense" refers to the conventional meaning whereas "use" refers to the contextual meaning (Haspelmath 2003: 212). On most occasions, it is not easy to detect whether a meaning has been conventionalized as part of semantics of hai or not. However, the semantic map method is completely neutral in this respect. When we define the functional nodes that will be presented in the conceptual space, we do not need to differentiate sense from use. Whether a particular function will be set as a functional node will eventually be tested out by different trials of cross-linguistic comparisons. For example, after reviewing the literature about the semantic analysis of repetitive grams, we arranged a template that contains far more nodes than what has been represented on the current conceptual space. After the first round of survey, it is found that some of the notions are always expressed by one identical 
form across languages, such as Increment and Prolongation. As grams expressing Prolongation can always express Increment, we combine the notion Prolongation into Increment. Following the same way, we have tested out all the primitive features of all the functional nodes by different trials of investigation, and notions of Prolongation, Close to Expectation, and Out of Expectation are removed or combined into other nodes in the conceptual space presented in the preceding section. In the following, we will provide a detailed discussion about how SMM guides us to combine two uses of hai.

Apart from the abovementioned case of Prolongation, there are other notions that we had created in the first place but which were merged into other notions after cross-linguistic comparison. One such notion is Close to Expectation. As suggested by many studies cited earlier, hai could convey some subjective meanings to show “程度低 chengdu di 'low degree” (Gao 高增霞 2002: 31; Tong 童晓娥 2004: 450; Wu 武果 2009: 323), “基本满意 jiben manyi 'basic satisfaction”' (Gao 高順全 2011: 40; Guo 郭锐 2008: 11), and “勉强认同 mianqiang rentong 'grudging recognition”" (Shao 邵洪亮 2013: 80).

Here are some of the examples for these uses:

\section{Low degree}

(66) 母亲九十了,身体还硬朗。 muqin_jiushi_le, shenti_hai_yinglang mother_ninety_PFV, body_still_strong My mother is ninety years old, but still strong. (Gao 高增霞 2002: 31)

\section{Basic satisfaction}

(67) 一路上还顺利。 yilushang_hai_shunli journey_still_all right The journey was all right. (Guo 郭锐 2008: 11)

\section{Grudging recognition}

\section{(68)这件衣服还比较时尚。}

$$
\begin{aligned}
& \text { zhe_jian_yifu_hai_bijiao_shishang } \\
& \text { this_CLF_clothes_still_comparatively_fashionable }
\end{aligned}
$$

This piece of clothing is relatively fashionable. (Shao 邵洪亮 2013: 80)

In our opinion, the first sentence is ambiguous between a temporal reading and an evaluative reading whereas the second and the third one can only provide the evaluative reading. In this research, however, the three instantiations are all subsumed under the notion of Close to Expectation. ${ }^{10}$ This notion implies that the speaker believes the property/state of an object/event is close to his/her expectation but not up to a high standard. Therefore, it gives rise to the interpretation of "low degree" and is often accompanied by subjective evaluation of the speaker's "basic satisfaction" or "grudging recognition" towards the object. 
Apart from Mandarin Chinese, this use could also be found in the repertoire of the counterpart in other dialects. Yang 楊秀芳 (2004: 236) describes that as a counterpart of hai, “故” $k u\left(\mathrm{koP}^{11}\right)$ in Min Chinese could also express the "conservative" meaning (the same as Close to Expectation described above) and she argued that it is from the meaning of "continuation" that the "conservative" meaning is derived. Yang proposes a diachronic path of change to demonstrate the closeness between the two concepts. One of the examples is as follows.

(69) 極進, 然 故是第二流中人耳。(《世說新語品藻》New Account of Tales of the World - Evaluation)

$$
\begin{aligned}
& \text { ji_jin, ran__gu_shi_dier_liu_zhong_ren_er } \\
& \text { greatly_progressive, but_still_is_second_rank_among_people_SFP }
\end{aligned}
$$

'He has greatly improved, but is still among the second-rate talkers.' (Yang 楊秀芳 2004: 228)

Just as in the example for "low degree," when leaving out the context, this sentence also shows blurring between the notion of Continuation and the notion of Close to Expectation. One can either interpret this sentence as "He has progressed a lot, but he is still a person of the second rank (as he was before)" or "He has progressed a lot, but he is still a person of the second rank (if he were given an evaluation)". However, if we take the context into consideration, we will find that it is the second interpretation that best suits the sentence.

(70)桓大司馬下都,問真長曰:「聞會稽王語奇進,爾邪?」劉曰:「極進,然故是第二流 中人耳!」桓曰:「第一流復是誰?」劉曰:「正是我輩耳!」(《世說新語品藻》) huan_dasima_xia_du, wen_zhenchang_yue: "wen_kuaiji_wang_yu_qi_jin, er_ye?” Liu_yue: “ji_jin, ran_gu_shi_dier_liu_zhong_ren_er!" huan_yue: "diyi_liu_fu_shi_shui?" liu_yue: "zheng_shi_wo_bei_er!" ${ }^{12}$ Huan_minister_come_capital, ask_Zhenchang_say: "hear_Kuaiji_King_talk (skill)_extraordinary_advance, this__SFP(interrogative)?” Liu_say: "great_improve, but_still_is_second_rank_among_people_SFP(affirmative)!" Huan_say: "first_rank_again_COP_who?" Liu_say: "exactly_ COP_1SG_people of a certain rank_ SFP(affirmative)!"

'Minister Huan came to the capital, and asked Liu Zhenchang, "I heard that the King of Kuaiji made an extraordinary improvement in his idle-talk skills; is it true?" Liu replied, "(He) has greatly improved, but is still (counted as) a second-rate talker". Huan asked, "Then who are first-rate talkers?" Liu replied, "Exactly people like you and me."

Based on the context, Yang 楊秀芳 (2004) deduces that it is the evaluative (rather than the continuative) use that the sentence implies, and the sentence could be interpreted as "He could basically be counted as a person of the second rank. (Ibid: 228)" to show the "conservative" judgment.

When we expand our view beyond Chinese, we find this conceptual correlation between Continuation and Close to Expectation in some Indo-European languages. For instance, English still is reported as having a kind of "marginal" use (König 1977; Michela 2004), which conspicuously resembles the notion Close to Expectation. 
(71) Compact cars are still fairly safe; subcompacts start to get dangerous. (Michela 2004: 127)

Michela (2004: 127) proposes that "compact cars are not particularly safe (even though they are safe) and that safer cars have already been discussed in the context in which it is uttered". In light of this interpretation, still can also express the notion of Close to Expectation.

Although the diachronic data in Chinese and the synchronic data in English have both shown the affinity between the notion of Continuation and Close to Expectation, it requires more direct evidence to further ascertain the relation between the two notions. In our investigation, we have included the above sentence into the questionnaire for cross-linguistic investigation, and the data shows that most languages use the same form for both Continuation and Close to Expectation (Table 9).

The above data shows that the notion of Continuation, Decrement, and Close to Expectation are closely connected. It has been demonstrated earlier by data type 11, 13, 23, 24, 25, 27, 28, 30, 31, and 32 that Continuation and Decrement can be expressed by different repetitive grams. We can set this pair of correlation aside. As in our investigation, the function of Close to Expectation is always expressed by the same form that denotes Continuation, we believe this pattern demonstrates that the notion of Close to Expectation should be considered as an automatic extension of Continuation. This is the reason why in the conceptual space that we proposed in the previous section, there is no such conceptual node as Close to Expectation. Besides, this cross-linguistic observation also provides robust support for not separating the use of Close to Expectation from the use of Continuation for the characterization of hai.

The data provides the relation between Close to Expectation and Continuation from the inductive view. In fact, this adjacency can also be explained from the deductive perspective. We know that the notion Continuation expresses that a state/property that occurred at an earlier time remains at the speaking time. This is naturally accompanied by the implicature that the speaker assumes that there should be a change of state/ property at the utterance time. However, this change does not happen at the reference time. Therefore, the notion of Continuation is accompanied by a lag effect of change.

Table 9 Data that proves the affinity between Continuation and Close to Expectation

\begin{tabular}{|c|c|c|c|c|c|c|c|c|}
\hline Language form & $\mathrm{CON}$ & $C-E$ & DEC & G-D & INC & REP & I-S & SUP \\
\hline $\begin{array}{l}\text { Bengali: akhono; Hindi: abhi; Korean: ajik; Portuguese: ainda; } \\
\text { Turkish: hâla; Urdu: abhibi;F } \\
\text { Zhuang: lij }\end{array}$ & + & + & + & & & & & \\
\hline $\begin{array}{l}\text { Antigua and Barbuda Creole English: til; Indonesian: masih; } \\
\text { Japanese: mada; Persian: hanooz; Russian: vsjo eshcho; } \\
\text { Shona: -chiri; Thai: yang; Vietnamese: vân còn }\end{array}$ & + & + & + & + & & & & \\
\hline Tagalog: pa & + & + & + & + & + & & & \\
\hline Sichuan Yi: yip si & + & + & + & + & & & & + \\
\hline Serbian: jou & + & + & + & & + & + & & \\
\hline German: noch & + & + & + & + & + & + & + & \\
\hline Latvian: vēl; Tibetan: ta rong & + & + & + & + & + & + & & + \\
\hline $\begin{array}{l}\text { Southwestern Guanhua (Chongqing): 還 xai; Min Nan Chinese } \\
\text { (Yun'ao): 還 xã; Jin Chinese (Fangshan): 還 xan }\end{array}$ & + & + & + & + & & + & + & + \\
\hline Min Nan Chinese (Taipei): 再 ko? & + & + & + & + & + & + & + & + \\
\hline
\end{tabular}


The lag effect of change of the state/property along the time axis described by Continuation could be mapped onto the subjective domain. Therefore, the lag of expected state/property is turned into a lag of expected standard. This lag of expected standard is just what Close to Expectation implies. ${ }^{13}$

In so doing, we have provided highly empirical evidences of subsuming Close to Expectation into Continuation in the semantic repertoire of Chinese hai. Following the same vein, other disputed categorizations of the different semantic meanings of Chinese hai can also be properly corrected by the SMM model. We can thus provide a holistic picture about the semantic map of Chinese hai as illustrated below (Fig. 21).

Similarly, the semantic maps of Chinese zai and you can also be shown as below (Figs. 22-23).

The above semantic maps demonstrate that the SMM can not only provide the semantic repertoire of the three grams at the right level of generalization but also reveals "a coherent chunk of a universal network (Haspelmath 2003: 214)" of the related functions. It is what its rival--the monolingual approach fails to do.

Besides, the semantic maps as shown above can also provide insights for us to solve some long-standing issues in Chinese. One heated topic is the differences of the Repetition functions of hai and zai. The semantic maps suggest that the Repetition function of hai is closely related to the function of Inverted Sequence whereas the Repetition function of zai is connected with the function of Increment. This suggests that the Repetition functions of hai and zai come from different conceptual sources, and our hypothesis is that hai expressing Repetition emphasizes the "similar" feature shared by Repetition and Inverted Sequence while zai expressing Repetition emphasizes the "increasing" feature shared by Repetition and Increment. Argumentation on this hypothesis will be provided in a separate study.

\section{Discussion}

In this research, we mainly illustrated how the notion of Repetition is connected to other relevant notions like Continuation and Increment. The geometrical configuration repeated below has been verified by all the first-hand and second-hand data with no exception, thus enjoying universal validity (Fig. 24).

With the insight obtained from constructing the above conceptual space, we have discussed some disputed issues concerning Chinese repetitive adverbs. By presenting two extreme approaches to the analysis of hai which take the "abstractionist" position

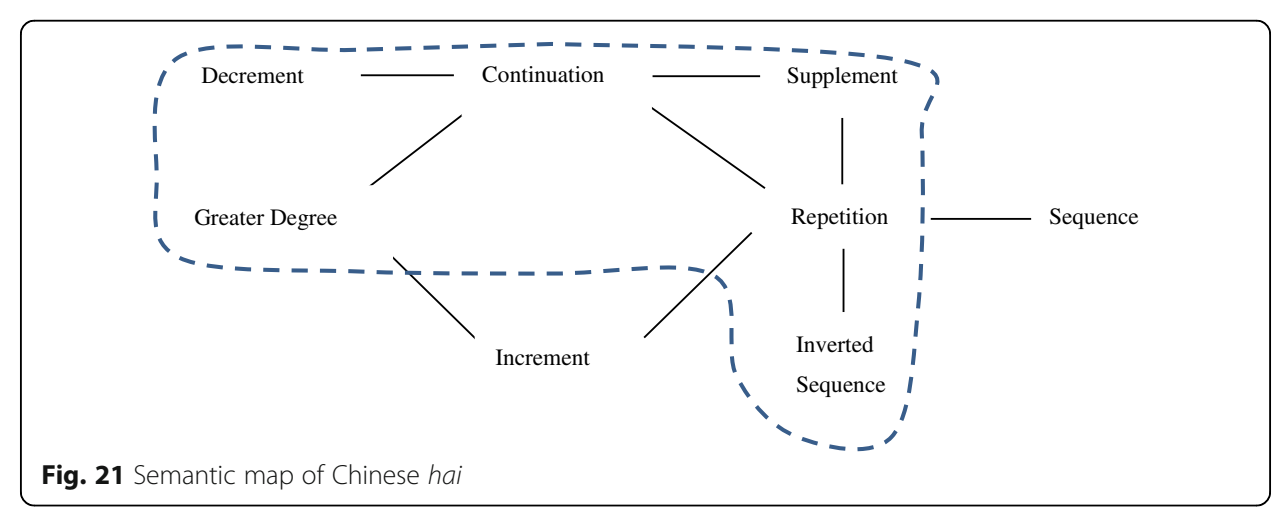




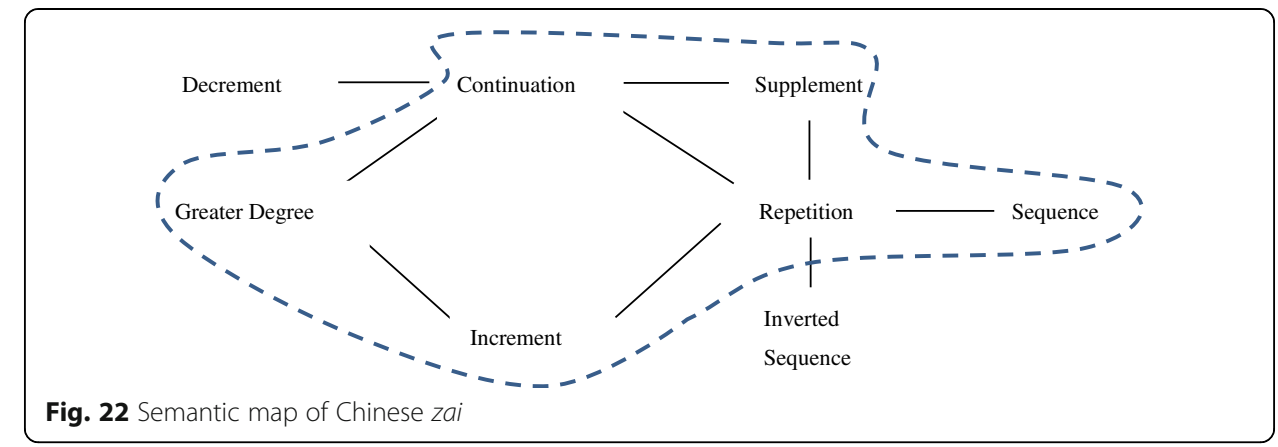

and the "polysemist" position, respectively, we demonstrate that neither of these approaches could objectively suggest whether two functions attached to a form should be combined or separated, as both are based on personal introspection. This disadvantage, however, could be avoided if we take the cross-linguistic perspective as the decision between combining and separating is completely based on the empirical data.

For researchers whose research interests are more related to individual languages, they may raise questions like how to relate the conceptual space to the study of adverbs in a language like Chinese, or what is the significance of adopting this particular approach. To satisfy queries like this, we have arranged Section 5 to briefly exemplify how we could employ the insights obtained from SMM studies to solve specific issues in individual languages like Chinese.

Here, we also wish to add some additional remarks on this. Section 5 only presented one example for the application of the semantic map approach, and it is far from presenting a complete list of the problems that the SMM approach can cover, and maybe the instances in this section are not the best examples that could fully reveal the advantages of SMM approach either. However, what we would like to emphasize here is that the conceptual spaces established through empirical data are theory-free, and therefore, they have a high degree of validity. In fact, it is very common to see that a conceptual space is established with an intention to solve some problems in a particular domain, but later, it turns out to be able to provide unexpected insight to solve some other issues.

For instance, based on Haspelmath (2003), Zhang 张敏 (2008) presents a conceptual space that reflects universal connective patterns for oblique roles. Unexpectedly, the same conceptual space can also account for a different (albeit related) phenomenon, i.e., the regularity in "transitivity prominence" in some isolating languages of the SVO

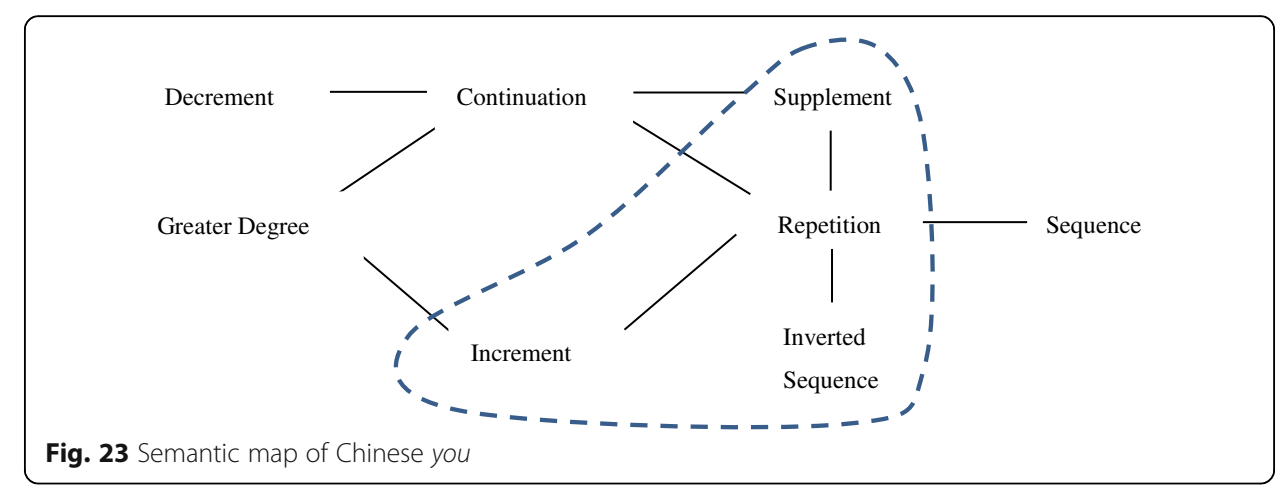




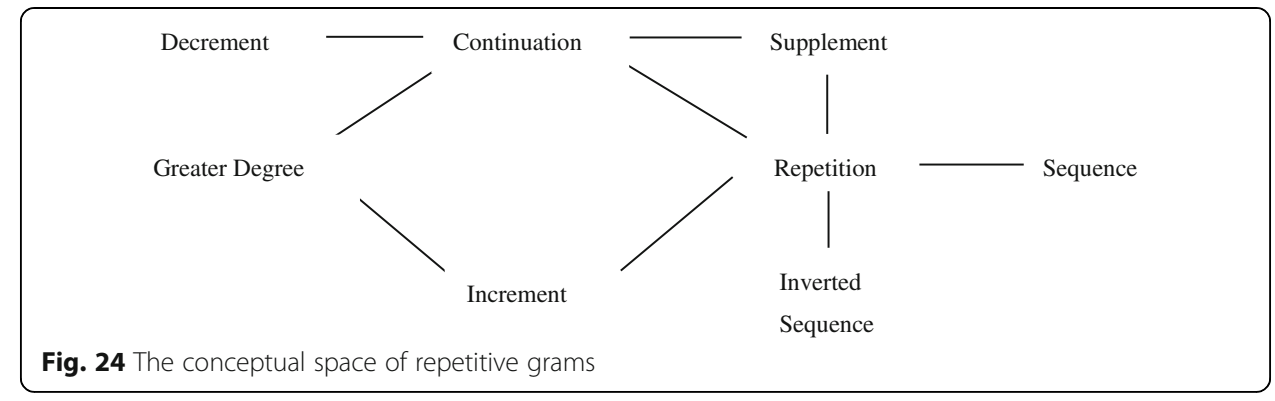

type like Chinese, Vietnamese, and Hmong. Unlike many SOV languages like Japanese and Korean, where only the patient argument can serve as the direct object of a verb, in Chinese, Vietnamese, Hmong, and many other mainland Southeast Asian SVO languages, in addition to patient objects, transitive verbs (and even some intransitive verbs) may take direct objects in the roles like agent, instrumental, manner, locative, and purpose. Interestingly, all such direct-object roles form a continuous region in one way or another on the conceptual space of indirect roles.

Another case is Haspelmath (1997), a canonical semantic map study on the syntax and semantics of indefinite pronouns. In a very recent study by Lee et al. (2014), it is found that even in the field of discourse analysis, the extended uses of what-based interrogative expressions in Chinese also present similar patterns as indicated in the conceptual space of Haspelmath (1997).

These examples demonstrate that even if a conceptual space does not instantly suggest any explicit account for a specific issue in an individual language, its significance, however, may gradually emerge in the future, covering the explanation of more and more issues.

In this sense, we have every reason to believe that the conceptual spaces established in this research are very promising in solving many more issues in Chinese and other languages alike.

\section{Endnotes}

${ }^{1}$ The capitalized words refer to functional nodes, which will be defined in detail in later discussion.

${ }^{2}$ Example sentences that come from reference grammar are attached with citations, and the ones without citations are from our own investigation.

${ }^{3}$ Chinese adverbs 更 geng 'even more' and 較 jiao 'rather' share similar function with hai in some context; however, they are not investigated in this study. The reason is the two grams are not multifunctional.

${ }^{4}$ Due to the extensiveness of the literature on hai, we only list the studies that concern the different uses of hai.

${ }^{5}$ It is mathematically possible that a language may use one form to denote Repetition and Greater Degree, in which case the one-dimensional connective pattern shown in Fig. 3 will be changed into a two-dimensional loop. For a detailed discussion about loop in cross-linguistic comparison, the reader is referred to Zhang 张敏 (2008). Among all the first-hand data and the second-hand data that we collected in this research, no such data is found to express only Repetition and Greater Degree. 
${ }^{6}$ For better display, the terms for each of the notions will be abbreviated by capitalizing the first three letters; the notions Inverted Sequence and Greater Degree will be shortened as "I-S" and "G-D" respectively.

${ }^{7}$ More data that could verify the connection between Sequentiality and Repetition will be provided in section 4.2.3.

${ }^{8}$ The two boxes here indicate the lack of corresponding Chinese characters for the two phonetic forms, following Lin 林伦伦 (2006)

${ }^{9}$ There are other studies that also propose an abstract model of hai and try to subsume all the different uses of hai under the scalar model. Gao 高增霞 (2002) develops the scalar model further to argue that hai could trigger a temporal scalar in the "continuation" use, a rank order in the "polarity" use and an expectation scalar in the "mirative" use. Because of the kinship it bears to the model in Liu (2000), we will not provide a detailed review here.

${ }^{10}$ The reason of subsuming the uses of low degree, basic satisfaction, and grudging recognition into one node of close to expectation is the same with the reason we combine different nodes into one comprehensive node. If cross-linguistic data always tend to use one gram to denote the different functions, it is suggested that these functions be subsumed under one node in the conceptual space.

${ }^{11}$ According to Yang 楊秀芳 (2004), in different subdialects of Min, the phonetic form of this lexical item differs slightly.

${ }^{12}$ Yang 楊秀芳 (2004) is in Chinese, and the English translations are mine.

${ }^{13}$ Apart from "close to expectation," there is also another notion "out of expectation" that we have considered before our first trial of investigation. However, the notion "out of expectation" shows a far more complex pattern than "close to expectation." The reason is that "out of expectation" could have various sources. For instance, it could be caused by an unexpected newly added information to the speaker like in the sentence “我差點忘了! 我還有個會要開! wo chadian wang le! wo hai you ge hui yao kai! 'I almost forgot! I still have a meeting to attend!' The added event is a completely new piece of information to the speaker, and it brings the sense of "unexpectedness." However, it can also come from the notion of "continuation” like in the sentence “你還沒有出發?! ni hai meiyou chufa? 'You haven't set off yet?!" In this case, it can also denote a sense of mirative, but it apparently comes from the notion of "continuation." Besides, in our investigation, many languages use phonetic rather than lexical devices to encode the notion. So far, we lack of enough evidence to show how this notion is connected to other notions in the conceptual space, but we believe this line is well worth pursuing.

\footnotetext{
Abbreviations

1: First person; 2: Second person; 3: Third person; ACC: Accusative; AF: Agentive focus marker; AUX: Auxiliary; CLF: Classifier; CM: Comparative marker; COP: Copula; C: Complement; DM: Discourse marker; FIL: Filer; INDF: Indefinite; LNK: Ligature; LOC: Locative; NEG: Negative; NOM: Nominative; PASS: Passive; PF: Patientive focus marker; PFV: Perfective; POL: Polite speech level; PST: Past; PL: Plural; PROG: Progressive; RECP: Reciprocal; SBJV: Subjunctive; SFP: Sentence final particle; SH: Subject honorific suffix; SG: Singular; TC: Topic-contrast adverb; TOP: Topic
}

\section{Acknowledgements}

I am grateful to Professor Min Zhang, who patiently supervised my dissertation, which is the basis for this paper. I also thank two anonymous reviewers for their thoughtful comments on earlier versions of it. Of course, I am responsible for any possible errors. The work has been supported by Hong Kong Research Grants Council (Project No. 641913). 


\section{Publisher's Note}

Springer Nature remains neutral with regard to jurisdictional claims in published maps and institutional affiliations.

Received: 5 June 2016 Accepted: 28 July 2017

Published online: 26 September 2017

\section{References}

Akitani, Hiroyuki 秋谷裕幸. 2005. The Eastern Min dialect at South Zhejiang 浙南的闽东区方言. Taipei: Institute of Linguistics, Academia Sinica.

Anderson, Lloyd B. 1982. The "perfect" as a universal and as a language-particular category. In Tense-aspect: between semantics and pragmatics, ed. Paul J. Hopper, 227-264. Amsterdam/Philadelphia: John Benjamins.

Anderson, Lloyd B. 1986. Evidentials, paths of change, and mental maps: Typologically regular asymmetries. In Evidentially: The linguistic encoding of epistemology, ed. Wallace L. Chafe and Johanna Nichols, 273-312. Norwood: Ablex.

Biq, Yung-O. 1989. Ye as manifested on three discourse planes: polysemy or abstraction? In Functionalism and Chinese grammar, ed. James H.-Y. Tai and Frank F.S. Hsueh, 1-18. South Orange, NJ: Chinese Language Teachers Association.

Chang, Hong'en 常宏恩. 1986. A sketch on Lahu 拉祜语简志. Beijing: The Ethnic Publishing House.

Croft, William. 1991. Syntactic categories and grammatical relations: The cognitive organization of information. Chicago: University of Chicago Press.

Croft, William. 2001. Radical construction grammar: Syntactic theory in typological perspective. Oxford: Oxford University Press.

De Haan, Ferdinand. 2005. Modality in Slavic and semantic maps. In Modality in Slavonic languages: New perspectives, ed. Björn Hansen and Petr Karlik, 3-25. München: Otto Sagner.

Fan, Xiaolei 范晓蕾. 2011. The semantic map of possibility modality based on comparative evidence from Chinese dialects 以汉语方言为本的能性情态语义地图. Essays on Linguistics 语言学论从 43: 55-100.

Fillmore, Charles J., Paul Kay, and Mary C. O'Connor. 1988. Regularity and idiomaticity in grammatical constructions: The case of let alone. Language 64(3): 501-538.

Gao, Shunquan 高顺全. 2011. On the grammaticalization order and acquisition order of multi-meaning adverb hai 多 义副词“还”的语法化顺序和习得顺序. TCSOL Studies 华文教学与研究 42(2): 39-45.

Gao, Sixin, and Siyan Gao 高思欣 高思艳. 2007. The meaning of the adverb zai也谈副词“再”的语义. Journal of College of Chinese Language and Culture of Jinan University暨南大学华文学院学报 4: 55-59.

Gao, Zengxia 高增霞. 2002. The basic meaning of adverb hai 副词“还”的基本义. Chinese Teaching in the World 世界汉 语教学 60(2): 28-34.

Guo, Rui 郭锐. 2008. Semantic structure and semantic analysis of Chinese empty words 语义结构和汉语虚词语义分 析. Chinese Teaching in the World 世界汉语教学 4(4): 5-15.

Guo, Rui 郭锐. 2010. A semantic map study of adverbs related to "supplement" 副词的补充义与相关义项的语义地 图. Paper presented at the International Symposium for Comparative and Typological Research on Languages of China 中国语言的比较与类型学国际研讨会, Hong Kong, China.

Haspelmath, Martin. 1997. Indefinite pronouns. Oxford: Oxford University Press.

Haspelmath, Martin. 2003. The geometry of grammatical meaning: Semantic maps and cross-linguistic comparison. In The new psychology of language, ed. Michael Tomasello, vol. 2, 211-243. Mahwah, NJ: Lawrence Erlbaum.

Huang, Shu-Ping. 2007. A semantic map approach to cross-linguistic comparisons of polysemy: Implications for perspectivization theories. Tsing Hua Journal of Chinese Studies 37(2): 579-610.

Kemmer, Suzanne. 1993. The middle voice. Amsterdam/Philadelphia: John Benjamins.

König, Ekkehard. 1977. Temporal and non-temporal uses of 'noch' and 'schon' in German. Linguistics and Philosophy 1(2): 173-198.

Lee, Heeju, Danjie Su, and Hongyin Tao. 2014. A crosslinguistic study of some extended uses of what-based interrogative expressions in Chinese, English, and Korean. Paper presented at the 2nd Conference of the American Pragmatics Association, UCLA, Los Angeles.

Li, Charles N., and Sandra A. Thompson. 1981. Mandarin Chinese: A functional reference grammar. Berkeley: University of California Press.

Li, Dongmei 李东梅. 2015. On the meaning of "stay at the earlier stage of a process" of adverb hai 副词“还”的“停留于 发展过程中的早期阶段”义. Chinese Language Learning 汉语学习 6: 28-36.

Li, Yunbing 李云兵. 2000. A study on Lachi language 拉基语研究. Beijing: The Ethnic Publishing House.

Li, Shulan, and Qian Zhong 李树兰,仲谦. 1986. A sketch on Xibe 锡伯语简志. Beijing: The Ethnic Publishing House.

Lin, Lunlun 林伦伦. 2006. A study on Leizhou Min dialect at West Guangdong 粤西闽语雷州话研究. Beijing: Zhonghua Book Company.

Liu, Feng-hsi. 2000. The scalar particle hai in Chinese. Cahiers de Linguistique - Asie Orientale 29(1): 41-84.

Lü, Shuxiang 吕叔湘 (ed.). 1980. Eight hundred words of modern mandarin 现代汉语八百词. Beijing: Commercial Press.

Michaelis, Laura A. 1996. Cross-world continuity and the polysemy of adverbial still. In Space, World and Grammar, ed. Gilles Fauconnier and Eve Sweetser. Chicago and London: The University of Chicago Press.

Michela, Ippolito. 2004. An analysis of still. Proceedings from Semantics and Linguistic Theory 14: 127-144.

Ouyang, Jueya, and Yiqing Zheng 欧阳觉亚, 郑 贻青. 1980. A study of Hlai 黎语简志. Beijing: The Ethnic Publishing House.

Shao, Hongliang 邵洪亮. 2013. On the metalinguistic use of the adverb haishi 副词 “还是” 的元语用法. Language Teaching and Linguistic Studies 语言教学与研究 4: 75-82.

Shao, Jingmin, and Chunhua Rao 邵敬敏 饶春华. 1985. The adverb you and related methodological issues 说“又”一—兼论副词的研究方法. Language teaching and Linguistic Studies 语言教学与研究 2: 4-16.

Shen, Jiaxuan 沈家煊. 2001. Two constructions with hai in Chinese 跟副词“还”有关的两个句式. Studies of the Chinese Language 中国语文 6: 483-493.

Shi, Xiyao 史锡尧. 1990. The semantic network of adverb you 副词“又”的语义及其网络系统. Language teaching and Linguistic Studies 语言教学与研究 4: 101-111. 
Shi, Xiyao 史锡尧. 1996 A semantic analysis of zai and the comparisons between zai and you “再” 语义分析并比较 "再"、“双". Chinese Language Learning 汉语学习 2: 8-12.

Sohn, Ho-min. 1994. Korean. London and New York: Routledge.

Sweetser, Eve E. 1986. Polysemy vs. abstraction: Mutually exclusive or complementary? Annual Meeting of the Berkeley Linguistics Society 12: 528-538.

The 1955/1957 Language Class, Department of Chinese Language and Literature, Peking University 北京大学中文系 1955/1957语言班. 1982. Examples and explanations of empty words in modern Chinese 现代汉语虚词例释. Beijing: Commercial Press.

Tong, Xiao-e 童小娥. 2004. The semantic evolution and the semantic network of adverb hai 副词“还”各义项的发展演 变及其语义网络系统. Journal of Southwest University for Nationalities. Humanities and Social Sciences 西南民族大 学学报 (人文社科版) 25(8): 448-452.

Van der Auwera, Johan, and Vladimir A. Plungian. 1998. Modality's semantic map. Linguistic Typology 2(1): 79-124.

Wang, Li 王力. 1944. The theory of Chinese grammar 中国语法理论. Beijing: The Commercial Press.

Wu, Guo 武果. 2009. The subjective use of the adverbial hai 副词“还”的主观性用法. Chinese Teaching in the World 世 界汉语教学 3: 322-333.

Xiang, Mengbing 项梦冰. 1997. A grammar study of Hakka at Liancheng 连城客家话语法研究. Beijing: Language and Culture Press.

Xie, Baiyu 谢白羽. 2011. The subjective meaning of the adverbial hai and its syntactical realization “还”的主观性及其 句法实现. Chinese Language Learning 汉语学习 3: 65-70.

Yang, Hanji, and Sheng Zhang 杨汉基, 张盛. 1993. A study of Dong language 侗语简志. Guiyang: Guizhou Ethnic Publishing House.

Yang, Hsiu-fang 楊秀芳. 2004. The grammaticalization of KU and its usage in Min dialects 論“故”的虛化及其在閩方言 中的表現. Bulletin of the College of Liberal Arts, National Taiwan University 臺大文史哲學報 60: 199-242.

Yeh, Meng. 1998. On hai in Mandarin. Journal of Chinese Linguistics 26(2): 236-280.

Zhang, Min 张敏. 2008. Universals and particulars manifested on spatial maps and semantic maps: On passive, causative, disposal, instrumental, beneficiary markers across Chinese dialects 空间地图和语义地图上的 “常” 与 '变': 以汉语被动、使役、处置、工具、受益者等关系标记为例. Paper presented at the Linguistics Institute, the Chinese Academy of Social Sciences, Beijing, China.

Zhang, Min 张敏. 2010. The semantic map model and its application to the study of multifunctional grams in Chinese 语义地图模型:原理、操作及在汉语多功能语法形式研究中的应用. Essays on Linguistics 语言学论从 42: 3-63. Zhang, Yisheng 张谊生. 2000. Studies on adverbs in modern Chinese 现代汉语副词研究. Shanghai: Xuelin Press.

Zhao, Shuhua 赵淑华. 1981. Dialogue on hai 关于“还”的对话. Language Teaching and Linguistic Studies 语言教学与研 究 1: 19-26.

Zwarts, Joost. 2010. Semantic map geometry: Two approaches. Linguistic Discovery 8(1): 377-395.

Submit your manuscript to a SpringerOpen ${ }^{\circ}$ journal and benefit from:

- Convenient online submission

- Rigorous peer review

- Open access: articles freely available online

- High visibility within the field

- Retaining the copyright to your article

Submit your next manuscript at $\gg$ springeropen.com 